\title{
Dimension-Enhanced Ultra-High Performance Liquid Chromatography/Ion Mobility-Quadrupole Time-of-Flight Mass Spectrometry Combined with Intelligent Peak Annotation for the Rapid Characterization of the Multiple Components from Seeds of Descurainia sophia
}

\author{
Simiao Wang ${ }^{1, \#}$, Xue $\mathrm{Li}^{1, \#}$, Boxue Chen ${ }^{1}$, Shitong $\mathrm{Li}^{1}$, Jiali Wang ${ }^{1}$, Jing Wang ${ }^{2}$, Mingshuo Yang ${ }^{3}$, \\ Xiaoyan $\mathrm{Xu}^{1}$, Hongda Wang ${ }^{1}$ and Wenzhi Yang ${ }^{1,}$ \\ ${ }^{1}$ State Key Laboratory of Component-Based Chinese Medicine, Tianjin Key Laboratory of TCM Chemistry and Analysis, Tianjin \\ University of Traditional Chinese Medicine, Tianjin, 301617, China \\ ${ }^{2}$ Waters Technology Co., Ltd., Beijing, 101102, China \\ ${ }^{3}$ School of Computing Science, University of Glasgow, Glasgow, G12 8RZ, UK \\ ${ }^{*}$ Corresponding Author: Wenzhi Yang. Email: wzyang0504@tjutcm.edu.cn \\ ${ }^{\text {\#}}$ Simiao Wang \& Xue Li contributed equally to this work \\ Received: 03 August 2021 Accepted: 08 September 2021
}

\begin{abstract}
The complex composition of herbal metabolites necessitates the development of powerful analytical techniques aimed to identify the bioactive components. The seeds of Descurainia sophia (SDS) are utilized in China as a cough and asthma relieving agent. Herein, a dimension-enhanced integral approach, by combining ultra-high performance liquid chromatography/ion mobility-quadrupole time-of-flight mass spectrometry (UHPLC/IMQTOF-MS) and intelligent peak annotation, was developed to rapidly characterize the multicomponents from SDS. Good chromatographic separation was achieved within $38 \mathrm{~min}$ on a UPLC CSH C18 $(2.1 \times 100 \mathrm{~mm}$, $1.7 \mu \mathrm{m}$ ) column which was eluted by $0.1 \%$ formic acid in water (water phase) and acetonitrile (organic phase). Collision-induced dissociation-MS ${ }^{2}$ data were acquired by the data-independent high-definition $\mathrm{MS}^{\mathrm{E}}\left(\mathrm{HDMS}^{\mathrm{E}}\right)$ in both the negative and positive electrospray ionization modes. A major components knockout strategy was applied to improve the characterization of those minor ingredients by enhancing the injection volume. Moreover, a self-built chemistry library was established, which could be matched by the UNIFI software enabling automatic peak annotation of the obtained $\mathrm{HDMS}^{\mathrm{E}}$ data. As a result of applying the intelligent peak annotation workflows and further confirmation process, a total of 53 compounds were identified or tentatively characterized from the SDS, including 29 flavonoids, one uridine derivative, four glucosides, one lignin, one phenolic compound, and 17 others. Notably, four-dimensional information related to the structure (e.g., retention time, collision cross section, $\mathrm{MS}^{1}$ and $\mathrm{MS}^{2}$ data) was obtained for each component by the developed integral approach, and the results would greatly benefit the quality control of SDS.
\end{abstract}

\section{KEYWORDS}

Descurainia sophia; multicomponent characterization; ultra-high performance liquid chromatography; ion mobility/quadrupole time-of-flight mass spectrometry; high-definition $\mathrm{MS}^{\mathrm{E}}$; flavonoid 


\section{Introduction}

Traditional Chinese Medicine (TCM), mostly derived from plants, is attracting more attention from a global scope [1]. It has been included in the system of alternative therapy, and is particularly effective in treating some chronic and prevalent diseases, such as COVID-19 [2]. Systematic elucidation of the chemical substances of TCM is helpful to explore the therapeutic basis and elaborate the quality standards to promote its modernization and globalization [3]. However, there are some obstacles hindering the internationalization of TCM. As a distinctive feature, the multiple parts of plants, such as roots [4], leaves [5], flowers [6], and seeds [7], etc., can be used as a source for TCM. Generally, herbal medicines contain various chemical components, which are featured by the co-existance of primary and secondary metabolites with wide spans of acidity-base properties and molecular masses, different polarities, and sharply different contents, etc. [8]. Therefore, it is difficult to perform a quality investigation of TCM. Increasing demands on the sensitive characterization of the known components (targeted), and meanwhile, having the ability to probe into those unknown (untargeted) necessitate the elaboration of powerful analytical techniques, such as liquid chromatography/mass spectrometry (LCMS) [9]. MS, by combining the negative and positive ionization modes or using different ionization patterns, can give good response to most of the natural components with ultra-high sensitivity. Moreover, the ability of $\mathrm{MS}^{\mathrm{n}}$ acquisition, by the alternate fragmentation mechanisms and flexible scan approaches, provides more options to facilitate the fit-for-purpose profiling and characterization of multiple components with significantly greater coverage on the components of interest [10]. Another milestone progress in herbal components analysis in recent years is the introduction of ion mobility mass spectrometry (IM-MS). It offers an additional dimension of separation based on the size, shape, and charge state of the gas-phase ions orthogonal of MS. Impressively, IM-MS coupled with LC, such as the ultra-high-performance liquid chromatography/ion mobility-quadrupole time-of-flight mass spectrometry (UHPLC/IM-QTOF-MS), is able to provide four-dimensional data (e.g., retention time, drift time, MS information and the response) of the components. IM-derived collision cross section (CCS) has the potential to discriminate among isomeric metabolites [11,12].

Descurainia sophia (L.) Webb ex Prantl., belonging to the Brassicaceae family, is a medicinal herb mainly distributed in Shandong, Hebei, Henan, Zhejiang, Inner Mongolia, and Gansu provinces of China $[13,14]$. The seeds of $D$. sophia (SDS) are used as the source for the TCM Descurainiae Semen (Ting-Li$\mathrm{Zi}$ ). The plants are harvested when the fruits are ripe in summer, dried, and the seeds are rubbed out with the impurities removed [15]. According to the basic theory of TCM, Descurainiae Semen has a pungent, bitter taste, and a severe cold property, which can relieve lung and asthma, and is also effective in relieving swelling [16-18]. To date, a number of studies have been reported on the phytochemistry of SDS, and a variety of compounds have been isolated [19-21]. These compounds include flavonoids, glucosinolates and isothiocyanates, phenylpropanoids, coumarins, cardiac glycosides, organic acids, and volatile oils, etc. Additionally, quality control on Descurainiae Semen has been conducted to identify and quantitatively assay the components contained. For instance, a UHPLC/Q-TOF-MS/MS method was established, by Meng et al. [14] which enabled the characterization of 14 constituents from SDS, including nine flavonoids, four fatty acids, and one cardiac glycoside. Li et al. [22] established an HPLC method to determine the content of quercetin-3- $O-\beta$-D-glucopyranosyl-7- $O-\beta$-D-gentiobioside in 28 batches of SDS samples, and suggested that its content is not less than $0.075 \%$. However, according to the report of Wang et al. [23] this flavonoid compound in SDS was unstable in water at high temperature in a long-term extraction process.

In the current work, we reported a dimension-enhanced integral approach, by combining UHPLC/IMQTOF-MS-based data-independent high-definition $\mathrm{MS}^{\mathrm{E}}\left(\mathrm{HDMS}^{\mathrm{E}}\right)$ and $\mathrm{UNIFI}^{\mathrm{TM}}$-facilitated computational peak annotation to rapidly profile and characterize the multiple components from SDS, especially those minor ones. Fig. 1 illustrates the overall technical roadmap for this strategy. For this purpose, numerous 
efforts were made to achieve better performance in both the resolution and sensitivity: 1) the chromatography (e.g., stationary phase, column temperature, and gradient elution program) and key parameters of the Vion ${ }^{\mathrm{TM}}$ IM-QTOF mass spectrometer (capillary voltage, cone voltage, and collision energy) were both carefully optimized; 2) a major components knockout strategy was utilized to boost the profiling and characterization of minor components by enhancing the injection volume; 3 ) a chemical library recording 232 known compounds was in-house established to guide the automatic peak annotation and components identification; and 4) streamlined workflows were created by applying $\mathrm{UNIFI}^{\mathrm{TM}}$ to process the obtained high-resolution CID (collision-induced dissociation)-MS ${ }^{2}$ data. As a result of these efforts, we could identify or tentatively characterize 53 compounds from SDS, with four-dimensional information with respect to each component (e.g., $t_{\mathrm{R}}$, drift time/CCS, $\mathrm{MS}^{1}$ and $\mathrm{MS}^{2}$ data) conveniently provided.
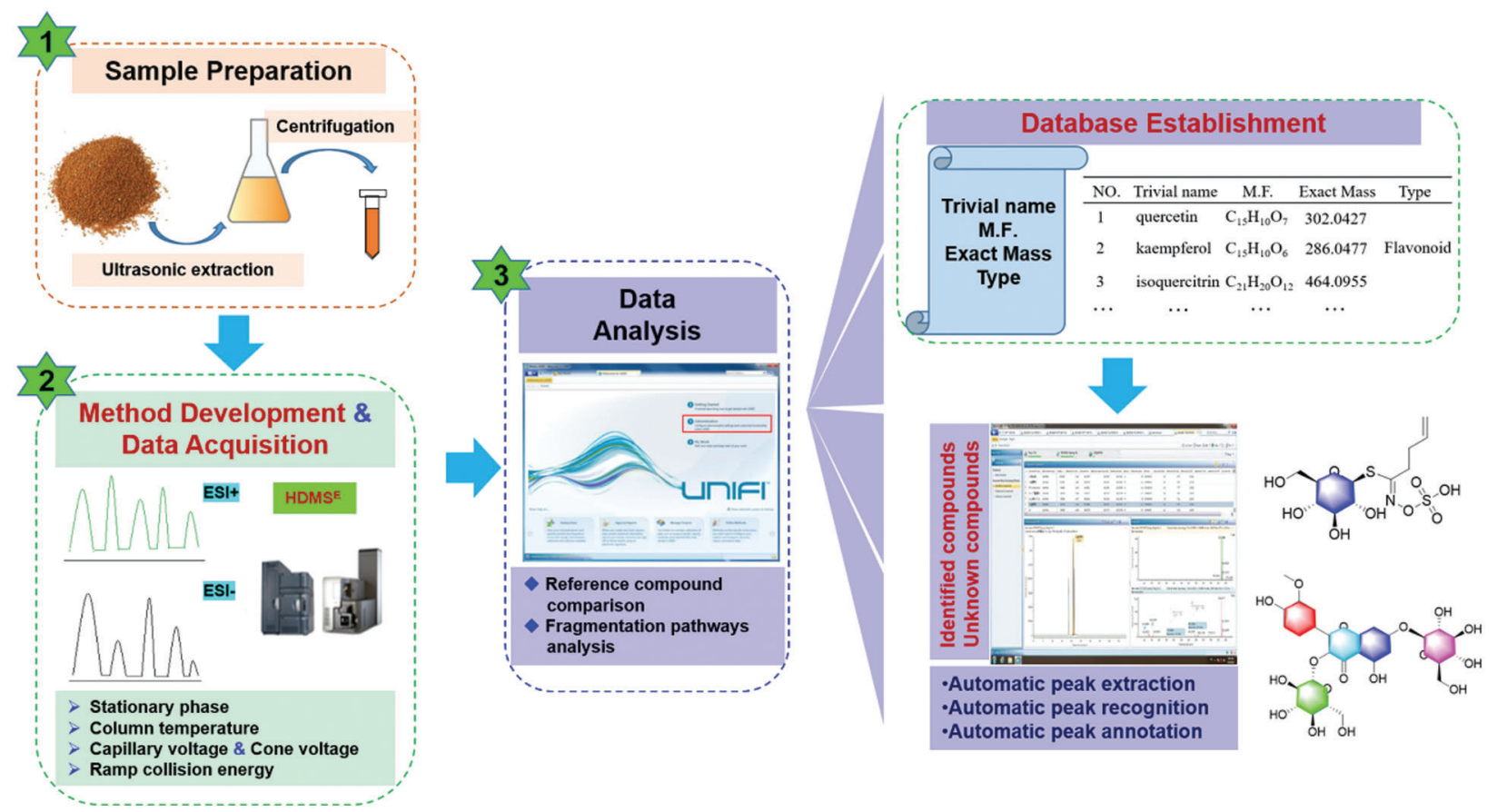

Figure 1: Schematic diagram for the rapid characterization of multiple components from the seeds of Descurainia sophia (SDS) by integrating dimension-enhanced UHPLC/IM-QTOF-MS and computational peak annotation because of the automatic MS information matching with the incorporated in-house library

\section{Materials and Methods}

\subsection{Materials}

Twenty compounds (Fig. 2) were used as reference compounds in this work. These compounds were isoquercitrin (1, $\left.\mathrm{C}_{21} \mathrm{H}_{20} \mathrm{O}_{12}\right)$, quercetin-7-O- $\beta$-D-glucopyranoside $\left(2, \mathrm{C}_{21} \mathrm{H}_{20} \mathrm{O}_{12}\right)$, kaempferol-3-Oneohesperidoside $\left(3, \mathrm{C}_{27} \mathrm{H}_{30} \mathrm{O}_{15}\right)$, kaempferol-3-O-rutinoside $\left(\mathbf{4}, \mathrm{C}_{27} \mathrm{H}_{30} \mathrm{O}_{15}\right)$, kaempferol $\left(\mathbf{5}, \mathrm{C}_{15} \mathrm{H}_{10} \mathrm{O}_{6}\right)$, luteolin $\left(6, \mathrm{C}_{15} \mathrm{H}_{10} \mathrm{O}_{6}\right)$, quercetin $\left(7, \mathrm{C}_{15} \mathrm{H}_{10} \mathrm{O}_{7}\right)$, apigenin $\left(\mathbf{8}, \mathrm{C}_{15} \mathrm{H}_{10} \mathrm{O}_{5}\right)$, isorhamnetin-3-O-glucoside (9, $\left.\mathrm{C}_{22} \mathrm{H}_{22} \mathrm{O}_{12}\right)$, kaempferol-7-O-glucoside (10, $\left.\mathrm{C}_{21} \mathrm{H}_{20} \mathrm{O}_{11}\right), \quad$ kaempferol-3-O- $\beta$-D-glucuronide (11, $\left.\mathrm{C}_{21} \mathrm{H}_{18} \mathrm{O}_{12}\right)$, apigenin-7-O- $\beta$-D-glucuronide $\left(12, \mathrm{C}_{21} \mathrm{H}_{20} \mathrm{O}_{10}\right)$, rutin $\left(\mathbf{1 3}, \mathrm{C}_{27} \mathrm{H}_{30} \mathrm{O}_{16}\right)$, eleutherodide A (14, $\left.\mathrm{C}_{33} \mathrm{H}_{40} \mathrm{O}_{20}\right)$, $\beta$-sitosterol $\left(15, \mathrm{C}_{35} \mathrm{H}_{60} \mathrm{O}_{6}\right.$ ), glucosinalbin $\left(\mathbf{1 6}, \mathrm{C}_{29} \mathrm{H}_{50} \mathrm{O}\right)$, scopolin $\left(17, \mathrm{C}_{14} \mathrm{H}_{19} \mathrm{NO}_{10} \mathrm{~S}\right)$, psoralen $\left(\mathbf{1 8}, \mathrm{C}_{16} \mathrm{H}_{18} \mathrm{O}_{9}\right)$, sinapic acid $\left(\mathbf{1 9}, \mathrm{C}_{11} \mathrm{H}_{6} \mathrm{O}_{3}\right)$, and vanillic acid $\left(\mathbf{2 0}, \mathrm{C}_{8} \mathrm{H}_{8} \mathrm{O}_{4}\right)$. They were purchased from Chengdu Desite Biotechnology Co., Ltd. (Chengdu, China) or Shanghai Standard Biotech. Co., Ltd. (Shanghai, China),. The drug material for the seeds of D. sophia was collected from 
Hebei Province of China (Batch No. 190302). The specimens were deposited at the authors' lab in Tianjin University of Traditional Chinese Medicine (Tianjin, China). HPLC-grade acetonitrile, methanol (Fisher, Fair Lawn, NJ, USA), formic acid (Sigma-Aldrich, MO, Switzerland), and ultra-pure water [in-house prepared using a Milli-Q Integral 5 water purification system (Millipore, Bedford, MA, USA)) were used.

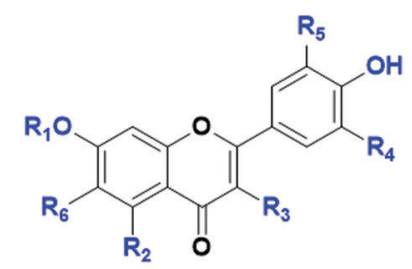

$1 \mathrm{R}_{1}=\mathrm{R}_{4}=\mathrm{R}_{6}=\mathrm{H}, \mathrm{R}_{2}=\mathrm{R}_{5}=\mathrm{OH}, \mathrm{R}_{3}=\mathrm{OGlc}$ $2 \mathrm{R}_{1}=\mathrm{Glc}, \mathrm{R}_{2}=\mathrm{R}_{4}=\mathrm{R}_{6}=\mathrm{H}, \mathrm{R}_{3}=\mathrm{R}_{5}=\mathrm{OH}$ $3 \mathrm{R}_{1}=\mathrm{Glc}(1,6) \mathrm{Rha}, \mathrm{R}_{2}=\mathrm{R}_{3}=\mathrm{OH}, \mathrm{R}_{4}=\mathrm{R}_{5}=\mathrm{R}_{6}=\mathrm{H}$ $4 \mathrm{R}_{1}=\mathrm{R}_{4}=\mathrm{R}_{5}=\mathrm{R}_{6}=\mathrm{H}, \mathrm{R}_{2}=\mathrm{OH}, \mathrm{R}_{3}=\mathrm{OGIc}(1,6) \mathrm{Rha}$ $5 \mathrm{R}_{1}=\mathrm{R}_{4}=\mathrm{R}_{5}=\mathrm{R}_{6}=\mathrm{H}, \mathrm{R}_{2}=\mathrm{R}_{3}=\mathrm{OH}$ $6 \mathrm{R}_{1}=\mathrm{R}_{3}=\mathrm{R}_{4}=\mathrm{R}_{6}=\mathrm{H}, \mathrm{R}_{2}=\mathrm{R}_{5}=\mathrm{OH}$ $7 \mathrm{R}_{1}=\mathrm{R}_{5}=\mathrm{R}_{6}=\mathrm{H}, \mathrm{R}_{2}=\mathrm{R}_{3}=\mathrm{R}_{4}=\mathrm{OH}$ $8 \mathrm{R}_{1}=\mathrm{R}_{3}=\mathrm{R}_{4}=\mathrm{R}_{5}=\mathrm{R}_{6}=\mathrm{H}, \mathrm{R}_{2}=\mathrm{OH}$ $9 \mathrm{R}_{1}=\mathrm{R}_{4}=\mathrm{R}_{6}=\mathrm{H}, \mathrm{R}_{2}=\mathrm{OH}, \mathrm{R}_{3}=\mathrm{OGlc}, \mathrm{R}_{5}=\mathrm{OCH}_{3}$ $10 \mathrm{R}_{1}=\mathrm{Glc}, \mathrm{R}_{2}=\mathrm{R}_{3}=\mathrm{OH}, \mathrm{R}_{4}=\mathrm{R}_{5}=\mathrm{R}_{6}=\mathrm{H}$ $11 \mathrm{R}_{1}=\mathrm{R}_{4}=\mathrm{R}_{5}=\mathrm{R}_{6}=\mathrm{H}, \mathrm{R}_{2}=\mathrm{OH}, \mathrm{R}_{3}=\mathrm{OGlC}$ $12 \mathrm{R}_{1}=\mathrm{Glc}, \mathrm{R}_{2}=\mathrm{R}_{3}=\mathrm{R}_{4}=\mathrm{R}_{5}=\mathrm{H}, \mathrm{R}_{6}=\mathrm{OH}$ $13 R_{1}=R_{5}=R_{6}=H, R_{2}=R_{4}=O H, R_{3}=O G l c(1,6)$ Rha

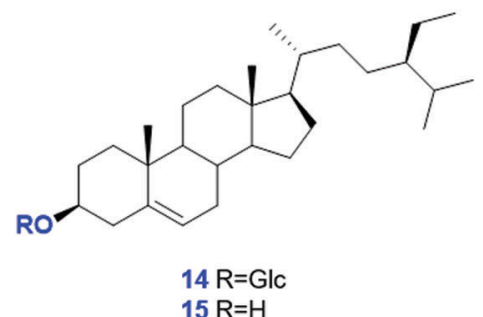

HO $15 \mathrm{R}=\mathrm{H}$<smiles>CC[C@H]1OC(Oc2cc3oc(=O)ccc3cc2OC)[C@H](O)[C@@H](O)[C@H]1O</smiles>
17

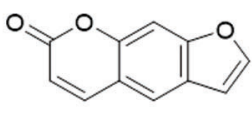

18

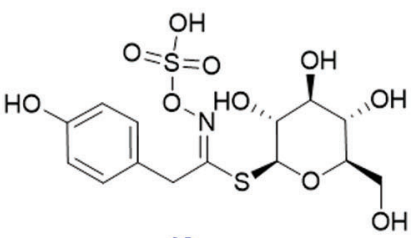

16<smiles>COc1cc(/C=C/C(=O)O)cc(OC)c1O</smiles><smiles>COc1cc(C(=O)O)ccc1O</smiles>

20

Figure 2: Chemical structures of 20 reference compounds used in the current work

\subsection{Sample Preparation}

An easy-to-implement ultrasonic extraction method was utilized for sample preparation from the SDS. In detail, $0.4 \mathrm{~g}$ of accurately weighed powder was soaked in a $15-\mathrm{mL}$ centrifuge tube containing $5 \mathrm{~mL}$ of methanol. After being vortexed for $2 \mathrm{~min}$, the sample was extracted on a water bath at $25^{\circ} \mathrm{C}$ with ultrasound assistance (power, $1130 \mathrm{~W}$; frequency, $40 \mathrm{kHz}$ ) for $40 \mathrm{~min}$. The extract was centrifuged for $10 \mathrm{~min}$ at $3,219 \mathrm{~g}$ (equal to 4,000 revolutions per min). The supernatant was further transferred into a $10-\mathrm{mL}$ volumetric flask. The extraction process was repeated by using another $4 \mathrm{~mL}$ of methanol. The pooled supernatant was diluted to a constant volume $(10 \mathrm{~mL})$, and it was then well mixed. The solution was centrifuged at $11,481 \mathrm{~g}(14,000$ revolutions per min) for $10 \mathrm{~min}$, and diluted reaching a final concentration of drug material of $10 \mathrm{mg} / \mathrm{mL}$.

\subsection{UHPLC/IM-QTOF-MS}

Metabolites profiling of SDS was performed on the ACQUITY UPLC I-Class/Vion ${ }^{\text {TM }}$ IM-QTOF system (Waters Corporation, Milford, MA, USA). A Waters Acquity UPLC CSH C18 $(2.1 \times 100 \mathrm{~mm}$, $1.7 \mu \mathrm{m})$ column hyphenated with a VanGuard Pre-column $(2.1 \times 50 \mathrm{~mm}, 1.7 \mu \mathrm{m})$ maintained at $30^{\circ} \mathrm{C}$ was used for the UHPLC separation. A binary mobile phase, composed by $0.1 \%$ formic acid in $\mathrm{H}_{2} \mathrm{O}$ (water phase: A) and $\mathrm{CH}_{3} \mathrm{CN}$ (organic phase: B), ran at $0.3 \mathrm{~mL} / \mathrm{min}$ in consistency with an optimal gradient program: 0-3 min, 2\% (B); 3-5 min, 2\%-10\% (B); 5-7 min, 10\% (B); 7-10 min, 10\%-13\% (B); 10-15 min, 13\% 21\% (B); 15-21 min, 21\% -28\% (B); 21-24 min, 28\%-40\% (B); 24-26 min, 40\% $-65 \%$ (B); 26-31 min, 65\%-85\% (B); 31-35 min, 85\%-100\% (B); and 35-38 min, 100\% (B). An aliquot of $3 \mu \mathrm{L}$ of the test solution was injected onto the column for analysis.

High-accuracy MS data for structural elucidation were acquired on a Vion ${ }^{\text {TM }}$ IM-QTOF mass spectrometer in both the positive and negative electrospray ionization (ESI) modes by data-independent 
$\mathrm{HDMS}^{\mathrm{E}}$ (Waters). The LockSpray ion source was equipped adopting the following parameters: capillary voltage, $1.5 \mathrm{kV}$; cone voltage, $60 \mathrm{~V}$; source offset, $80 \mathrm{~V}$; source temperature, $120^{\circ} \mathrm{C}$; desolvation gas temperature, $500^{\circ} \mathrm{C}$; desolvation gas flow $\left(\mathrm{N}_{2}\right), 800 \mathrm{~L} / \mathrm{h}$; and cone gas flow $\left(\mathrm{N}_{2}\right), 50 \mathrm{~L} / \mathrm{h}$. Default parameters were defined for the travelling wave IM separation [24,25]. The QTOF analyzer scanned over a mass range of $m / z 100-1500$ at a low collision energy of $6 \mathrm{eV}$ at $0.3 \mathrm{~s}$ per scan $\left(\mathrm{MS}^{1}\right)$. Ramp collision energy (RCE) of $20-40 \mathrm{eV}$ was set in high-energy channel for $\mathrm{HDMS}^{\mathrm{E}}$. MS data calibration was conducted by constantly infusing the leucine enkephalin solution (Sigma-Aldrich; $200 \mathrm{ng} / \mathrm{mL}$ ) at a flow rate of $10 \mu \mathrm{L} / \mathrm{min}$. CCS calibration was conducted according to the Manufacture's guidelines by using a mixture of calibrants [26].

\subsection{Data Analysis}

Uncorrected $\mathrm{HDMS}^{\mathrm{E}}$ data in Continuum format were corrected and processed by using the UNIFI ${ }^{\mathrm{TM}}$ 1.9.3.0 software (Waters). UNIFI could efficiently perform data correction, peak picking, and peak annotation [24,25]. Key parameters of UNIFI were set as follows. Find 4D Peaks (only set in HDMS ${ }^{\mathrm{E}}$ ): High-energy intensity threshold, 1000.0 counts; low-energy intensity threshold, 500.0 counts. Target by mass: Target match tolerance, $10.0 \mathrm{ppm}$; screen on all isotopes in a candidate, generate predicted fragments from structure, and look for in-source fragments; fragment match tolerance, $10.0 \mathrm{ppm}$. Adducts: Positive adduct was $+\mathrm{H}$. Lock Mass: Combine width, 3 scans; mass window, $0.5 \mathrm{~m} / \mathrm{z}$; reference mass, 556.2766; reference charge, +1 . Adducts: Negative adduct was $-\mathrm{H}$. Lock Mass: Combine width, 3 scans; mass window, $0.5 \mathrm{~m} / \mathrm{z}$; reference mass, 554.2620; reference charge, -1 .

\subsection{Creation of an in-House Library Incorporated into UNIFI ${ }^{T M}$}

Considering the restricted coverage of the commercial library on TCM components, we had the in-house library as a resource, which could guide the automatic annotation by UNIFI [24,25,27]. A systematic summary on the phytochemical reports of the seeds of D. sophia and Lepidium apetalum (two official plant sources for the TCM Ting-Li-Zi) was retrieved from multiple available databases (e.g., Web of Science, SciFinder, and CNKI, etc.). A chemical library was thus established recording the trivial name, molecular formula, and chemical structure for each compound. The collected structure information was input into an EXCEL file (.xls) in a format compatible with UNIFI, and each structure was drawn using ChemDraw Professional (Cambridge, USA), which was subsequently saved as a .mol file with the file name in consistency with the trivial name. The resulting EXCEL file and all structure files were incorporated into the UNIFI software, which can be utilized to efficiently annotate the obtained $\mathrm{HDMS}^{\mathrm{E}}$ data achieving structural elucidation for SDS.

\section{Results}

We integrated the dimension-enhanced $\mathrm{HDMS}^{\mathrm{E}}$ and UNIFI-facilitated intelligent peak annotation workflows, based on the UHPLC/IM-QTOF-MS, to enable the rapid profiling and characterization of the multi-components from SDS. Meanwhile, considering the differentiated ionization rates for the different classes of SDS components, both the negative and positive ESI modes were utilized to acquire the CID$\mathrm{MS}^{2}$ data.

As a result, good separation of the SDS components was accomplished by a reversed-phase UPLC CSH $\mathrm{C} 18$ column (column temperature: $30^{\circ} \mathrm{C}$ ) within 38 min using $\mathrm{CH}_{3} \mathrm{CN} / 0.1 \% \mathrm{FA}-\mathrm{H}_{2} \mathrm{O}$ as the mobile phase. Capillary voltage at $1.5 \mathrm{kV}$ and cone voltage at $60 \mathrm{~V}$ in ESI- could give satisfactory ion response, but seldom induce the in-source fragmentation. RCE of $20-40 \mathrm{eV}$ was able to acquire more balanced $\mathrm{MS}^{2}$ spectra than the setting of the fixed collision energy. The negative-mode CID-MS ${ }^{2}$ data were mainly used for structural elucidation, while the data obtained by ESI+ exerted complementarity. In the ESI- mode, one major peak was predominant, which thus hindered the characterization of the other relatively minor ones (Fig. 3). 
Thereby we applied the major components knockout strategy (the elutes at 7-8.8 min were automatically switched to the waste), by increasing the injection volume to $10 \mu \mathrm{L}$, which enabled the enrichment of a number of minor components. What's more, an in-house library of Ting-Li-Zi was established to aid the intelligent peak annotation by UNIFI. A total of 47 related documents were found, which involved 232 known compounds (including two alkaloids, two benzoic acids, three cardiac glycosides, 66 flavonoids, 35 glucosides, 9 lignin, 10 organic acids, five phenolic compounds, three phenolic acids, two phenylacetamides, one phenylacetonitrile, 3 phenylethylamines, 12 phenylpropanoids, one steroid, eight tobacco flavor anhydrides, one triterpenoid, 10 uridine derivatives, and 59 others (Table S1).
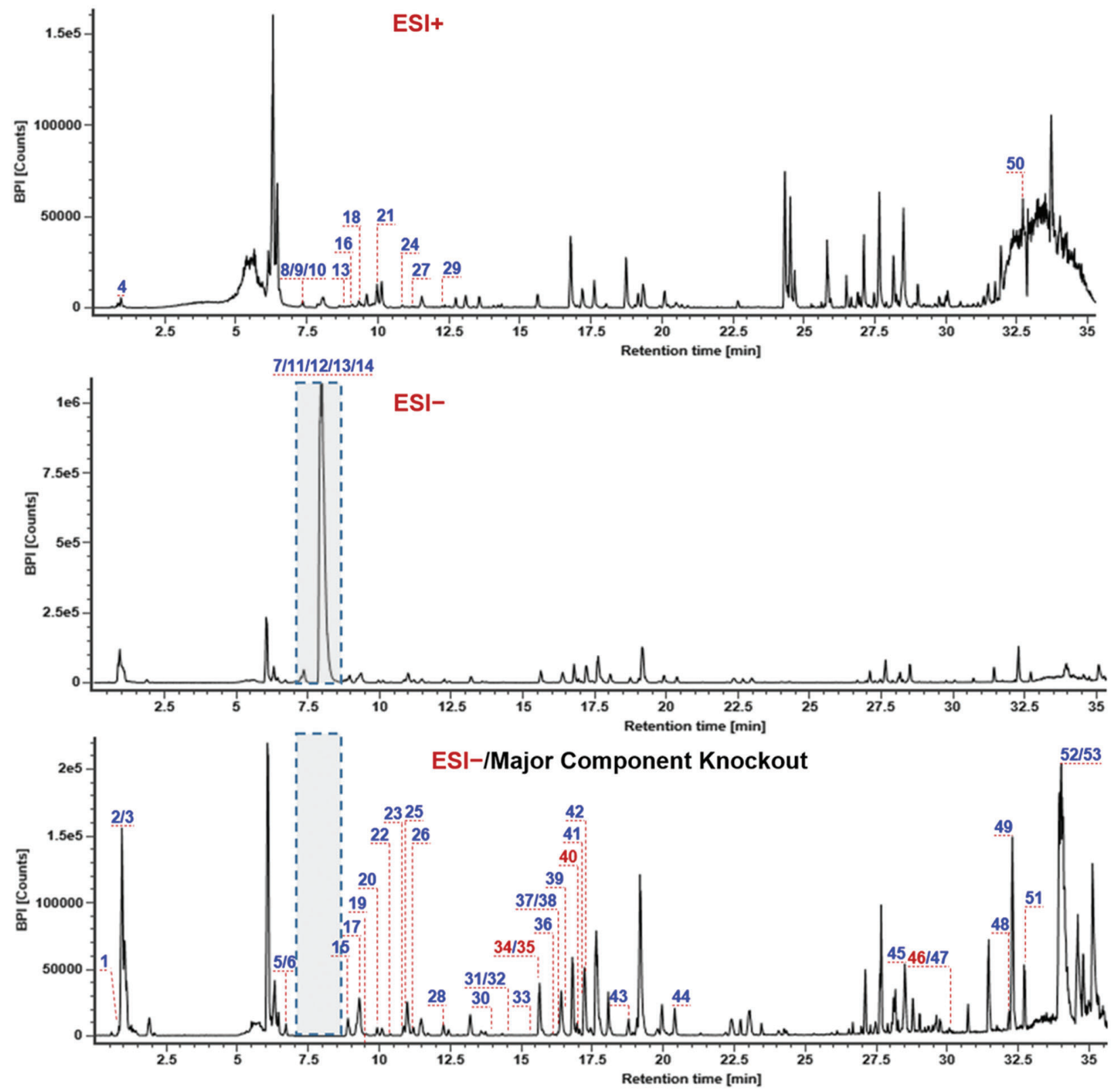

Figure 3: Base peak intensity chromatograms for the seeds of $D$. sophia obtained by $\mathrm{HDMS}^{\mathrm{E}}$ in the positive $(\mathrm{ESI}+)$ and negative (ESI-) modes with the peaks annotated with the numbering consistent with Table S2. A major components knockout strategy (eluates at 7-8.8 min switched to the waste) was utilized to enhance the characterization of minor components 
After the automatic matching between the determined CID-MS ${ }^{2}$ data with the predicted MS data (based on the in-house library) using UNIFI, combined with a subsequent confirmation step, a total of 53 compounds (Table S2 and Fig. 3) were identified or tentatively characterized from SDS by analyzing both the negative and positive CID-MS ${ }^{2}$ data. They included 29 flavonoids, one uridine derivative, four glucosides, one lignin, one phenolic compound, and 17 others. Notably, the CCS information for each characterized component is offered due to the enabling of the IM separation. The characterization of flavonoids and glucosinolates was illustrated in this work with representative compounds, and the others were outlined at the end of this section.

\subsection{Characterization of Flavonoids}

Flavonoids are an important class of bioactive components in SDS, and we were able to characterize 29 flavonoids based on the CID-MS ${ }^{2}$ data in the current work. Interestingly, the sugars in these flavonoid $O$-glycosides are limited to glucose (Glc) and rhamnose (Rha), which could be characterized by the typical neutral losses of $162.05 \mathrm{Da}$ and $146.06 \mathrm{Da}$, respectively. The structural differences are mainly embodied in the flavonoid aglycones, possibly as well as the glycosylation sites and the linkage patterns of multiple sugars which could not be exactly identified only by the MS information. The CID-MS/MS features of flavonoid $O$-glycosides were featured by the neutral loss of sugars and the production of deprotonated aglycone ions and their secondary fragments [28]. Here, the fragmentation pathways and characterization of compounds $18 \#\left(t_{R} 9.34 \mathrm{~min}\right), \mathbf{1 2} \#\left(t_{R} 8.75 \mathrm{~min}\right)$ and $15 \#\left(t_{R} 8.95 \mathrm{~min}\right)$ were illustrated (Fig. 4). The $\mathrm{MS}^{1}$ spectrum of compound 18\# gave a rich protonated precursor ion $\left([\mathrm{M}+\mathrm{H}]^{+}\right)$ at $\mathrm{m} / z 641.1716$ in the positive ESI mode, based on which its molecular formula was characterized as $\mathrm{C}_{28} \mathrm{H}_{32} \mathrm{O}_{17}$. In the CID-MS ${ }^{2}$ spectrum, a fragment, due to the neutral loss of the Glc moiety, was observed at $m / z 479.1181\left([\mathrm{M}+\mathrm{H}-\mathrm{Glc}]^{+}\right)$. In addition, the base peak ion at $m / z 317.0645$ should be the protonated aglycone after eliminating $2 \times \mathrm{Glc}\left([\mathrm{M}+\mathrm{H}-2 \mathrm{Glc}]^{+}\right)$, which could further lose the free radical $-\mathrm{CH}_{3}$ yielding a weak fragment at $\mathrm{m} / \mathrm{z} 302.0414$ (a homolytic fragmentation ion for the aglycone). The known flavonoid $O$-glycosides isolated from SDS only contain three flavonoid aglycones: isorhamnetin $\left(\mathrm{C}_{16} \mathrm{H}_{12} \mathrm{O}_{7}\right)$, quercetin $\left(\mathrm{C}_{15} \mathrm{H}_{10} \mathrm{O}_{7}\right)$, and kaempferol $\left(\mathrm{C}_{15} \mathrm{H}_{10} \mathrm{O}_{6}\right)$, and accordingly the aglycone moiety in compound 18\# should be isorhamnetin $\left(\mathrm{C}_{16} \mathrm{H}_{12} \mathrm{O}_{7}\right)$. The observation of free radical fragmentation of $-\mathrm{CH}_{3}$ could also testify this aglycone structure. Ultimately, this compound was tentatively characterized as isorhamnetin-3,7-di- $O-\beta$-D-glucopyranoside or isomer [14]. The fragmentation pathways of compound 12\# $\left(t_{R} 8.75 \mathrm{~min}\right)$ were analyzed based on the negative ESI-CID-MS ${ }^{2}$ data, which gave a rich deprotonated precursor ion $\left([\mathrm{M}-\mathrm{H}]^{-}\right)$at $\mathrm{m} / \mathrm{z}$ 625.1408, based on which the molecular formula of $\mathrm{C}_{27} \mathrm{H}_{30} \mathrm{O}_{17}$ could be characterized. Two major product ions, at $\mathrm{m} / z 463.0871\left([\mathrm{M}-\mathrm{H}-\mathrm{Glc}]^{-}\right)$and 301.0344 ([M-H-2Glc $\left.]^{-}\right)$, were generated by successively losing two Glc residues. The aglycone could match the known quercetin $\left(\mathrm{C}_{15} \mathrm{H}_{10} \mathrm{O}_{7}\right)$, and thus compound 12\# was tentatively characterized as quercetin-7- $O-\beta$-D-gentiobioside or isomer by comparison with the literature [17]. Compound 15\# $\left(t_{R}\right.$ $8.95 \mathrm{~min}$ ) was characterized as a tri-glycosidic flavonoid with a rich $[\mathrm{M}-\mathrm{H}]^{-}$precursor ion observed at $\mathrm{m} /$ $z$ 771.1990. Three major product ions were detected in the MS/MS spectrum at $m / z 609.1458,447.0931$, and 285.0398, which could be assigned as $[\mathrm{M}-\mathrm{H}-\mathrm{Glc}]^{-},[\mathrm{M}-\mathrm{H}-2 \mathrm{Glc}]^{-}$, and $[\mathrm{M}-\mathrm{H}-3 \mathrm{Glc}]^{-}$, respectively. The aglycone could match the known kaempferol $\left(\mathrm{C}_{15} \mathrm{H}_{10} \mathrm{O}_{6}\right)$, and thus Compound $15 \#$ was identified as kaempferol-3- $O-\beta$-D-glucopyranosyl-7- $O-\beta$-gentiobioside or isomer [20]. To sum up, among these 29 flavonoids characterized from SDS, 12 compounds thereof $(\mathbf{6} \# / \mathbf{7} \# / \mathbf{8} \# / \mathbf{9} \# / \mathbf{1 2} \# / \mathbf{1 3} \# / \mathbf{2 0} \# / \mathbf{2 6} \# / \mathbf{2 7} \# / \mathbf{3 4} \# /$ $\mathbf{3 7} \# / \mathbf{5 0} \#)$ have the aglycone of quercetin, $11(\mathbf{1 0} \# / \mathbf{1 5} \# / \mathbf{1 6} \# / \mathbf{2 2} \# / \mathbf{2 8} \# / \mathbf{2 9} \# / \mathbf{3 5} \# / \mathbf{3 6} \# / \mathbf{4 0} \# / \mathbf{4 2} \# / \mathbf{4 3} \#)$ with kaempferol, and 6 with isorhamnetin $(/ \mathbf{1 7} \# / \mathbf{1 8} \# / \mathbf{2 3} \# / \mathbf{2 4} \# / \mathbf{4 1} \# / \mathbf{4 6} \#)$. 


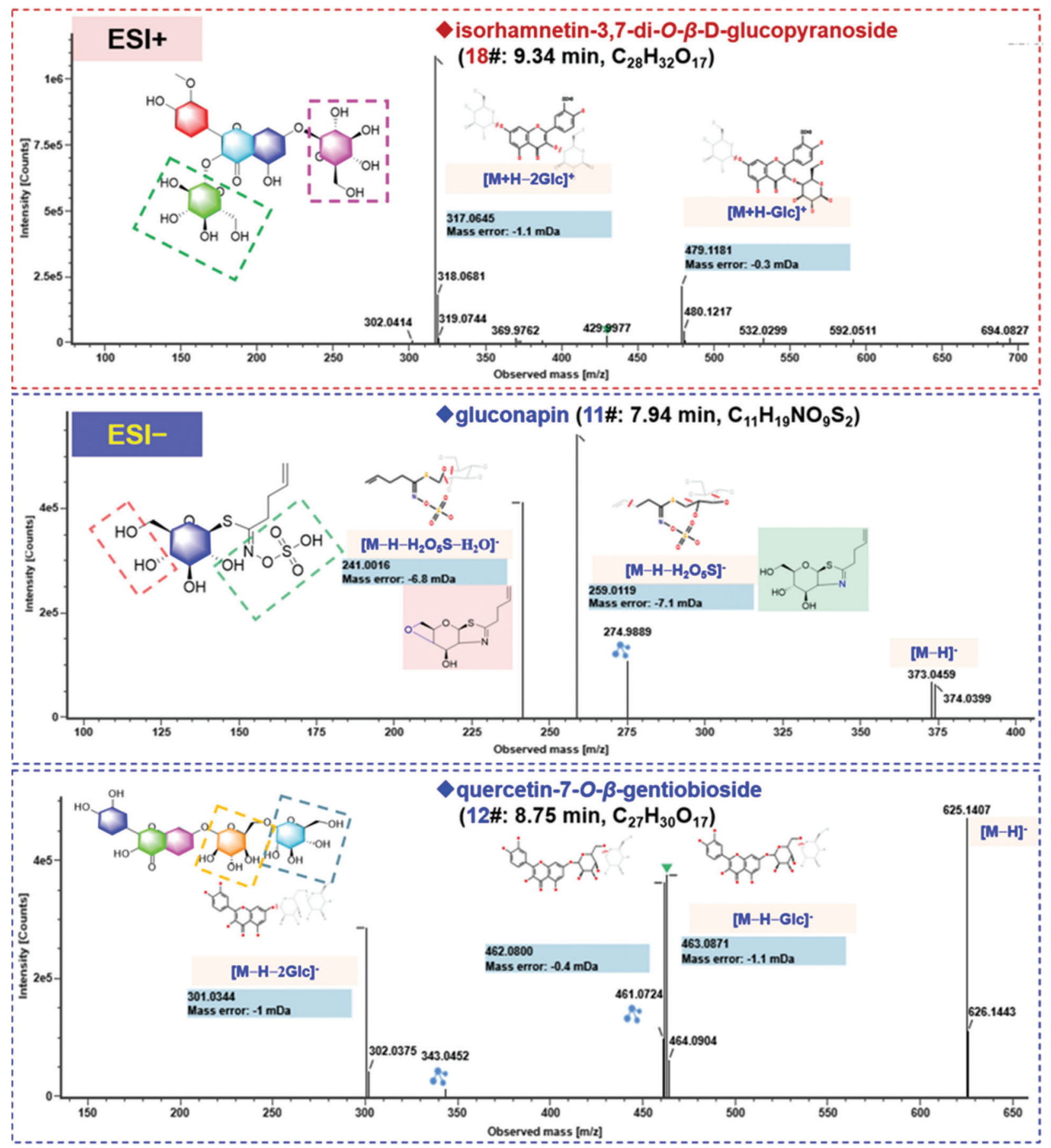

Figure 4: Continued 


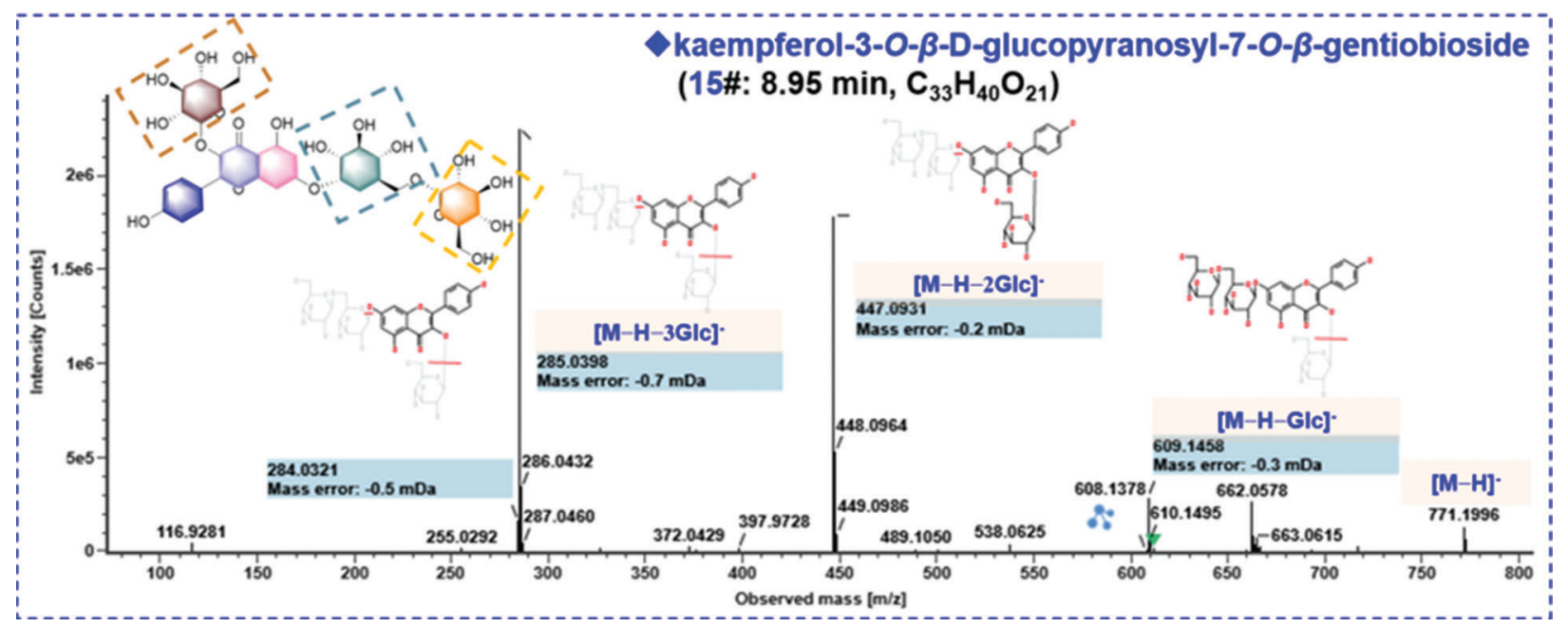

Figure 4: Annotation of the CID-MS ${ }^{2}$ spectra of the representative compounds for the flavonoids (compounds 18\#, 12\#, and 15\#) and the glucosinolate (compound 11\#), identified from the seeds of $D$. sophia based on both the positive and negative CID-MS ${ }^{2}$ data

\subsection{Characterization of Glucosinolates}

Isothiocyanates are the degradation products of glucosinolates ever isolated from SDS, including benzyl isothiocyanate, allyl isothiocyanate, 3-butenyl isothiocyanate, and 2-phenylethyl isothiocyanate, etc. [8]. Compound 11\# ( $\left.t_{R} 7.94 \mathrm{~min}\right)$ was observed in the negative ESI mode, with a rich deprotonated precursor ion $\left([\mathrm{M}-\mathrm{H}]^{-}\right)$at $\mathrm{m} / \mathrm{z}$ 372.0425. In its CID-MS ${ }^{2}$ spectrum, a fragment was observed at $\mathrm{m} / \mathrm{z} 259.0119$ $\left(\left[\mathrm{M}-\mathrm{H}-\mathrm{H}_{2} \mathrm{O}_{5} \mathrm{~S}\right]^{-}\right.$), together with its secondary fragment of $\mathrm{m} / \mathrm{z} 241.0016$ by losing a molecule of $\mathrm{H}_{2} \mathrm{O}$ $\left(\left[\mathrm{M}-\mathrm{H}-\mathrm{H}_{2} \mathrm{O}_{5} \mathrm{~S}-\mathrm{H}_{2} \mathrm{O}\right]^{-}\right)$(Fig. 4). By searching the literature, this compound was tentatively identified as gluconapin [29].

In addition to flavonoids and glucosinolates, one uridine derivative (2\#), one lignin (44\#), one phenolic compound (38 $)$, and 17 others $(1 \# / 3 \# / 4 \# / 5 \# / 14 \# / 19 \# / 21 \# / 25 \# / 30 \# / 33 \# / 39 \# / 47 \# / 48 \# / 49 \# / 51 / / 52 \# / 53 \#)$, were also tentatively characterized from SDS by analyzing their high-resolution $\mathrm{MS}^{1}$ and $\mathrm{MS}^{2}$ data, and comparison with the literature as well. For example, the compound 3\#, was observed in the negative ESI mode, with a rich deprotonated precursor ion $\left([\mathrm{M}-\mathrm{H}]^{-}\right)$at $m / z$ 341.1083. In its CID-MS ${ }^{2}$ spectrum, a fragment, due to the neutral loss of Glc, was observed at $\mathrm{m} / z 179.0555$ ([M-H-Glc] $]^{-}$). Accordingly, compound $\mathbf{3} \#$ was tentatively characterized as sucrose. Information for the other compounds characterized from SDS is detailed in Table S2.

\section{Discussion}

\subsection{Optimization of the Chromatography Condition}

In order to separate and identify as many components as possible from SDS, the reversed-phase UHPLC conditions were optimized in terms of the stationary phase, column temperature, and elution gradient program. Effects of different stationary phases were evaluated, including four Waters sub-2 $\mu \mathrm{m}$ particles packed UHPLC columns, CSH C18 $(2.1 \times 100 \mathrm{~mm}, 1.7 \mu \mathrm{m})$, BEH Shield RP18 $(2.1 \times 100 \mathrm{~mm}$, $1.7 \mu \mathrm{m}), \operatorname{BEH} \mathrm{C} 18(2.1 \times 100 \mathrm{~mm}, 1.7 \mu \mathrm{m})$, and $\operatorname{HSS} \mathrm{T} 3(2.1 \times 100 \mathrm{~mm}, 1.8 \mu \mathrm{m})$ (Fig. 5). Comparatively, most peaks could be separated on the CSH C18 column, and the peaks through the entire spectrum were more balanced than the other two columns. Therefore, we selected the CSH C18 column in this experiment. Moreover, the variations in column temperature $\left(25-40^{\circ} \mathrm{C}\right)$ could influence the retention of SDS constituents, and most peaks were resolved under $30^{\circ} \mathrm{C}$ (Fig. S1). After further adjustment of the elution gradient, satisfactory separation of the SDS components was achieved. 


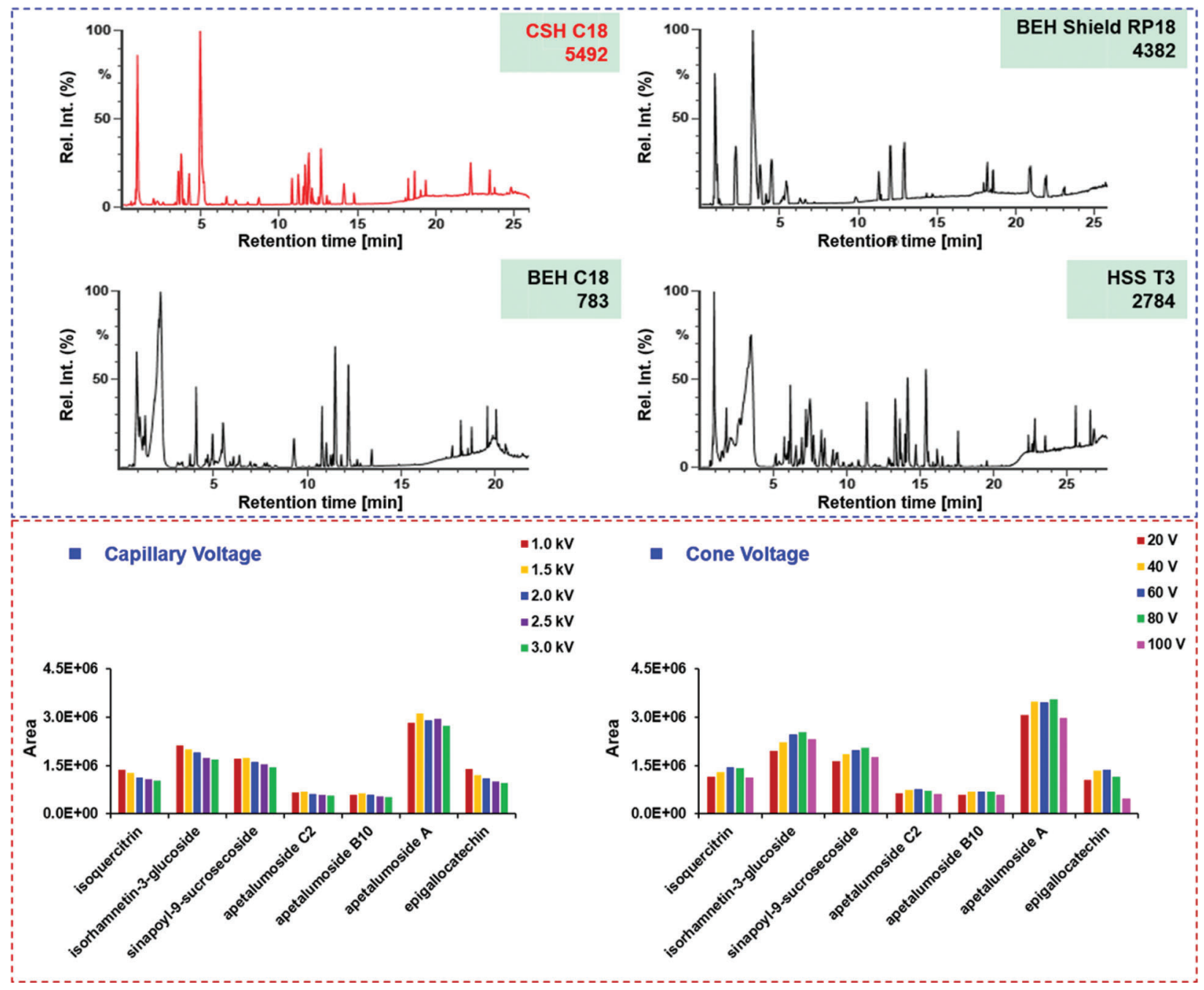

Figure 5: Screening of the candidate chromatographic columns and optimization of two key ion source parameters (capillary voltage and cone voltage) of the Vion ${ }^{\mathrm{TM}}$ IM-QTOF mass spectrometer for separating and characterizing the multicomponents from the seeds of D. sophia

\subsection{Optimization of Key Parameters on the Vion TM IM-QTOF Mass Spectrometer}

Key parameters that may affect the ion response (capillary voltage and cone voltage) and the fragmentation degree (RCE) of SDS components were optimized in the negative ESI mode. Capillary voltage $(1.0 / 1.5 / 2.0 / 2.5 / 3.0 \mathrm{kV})$ and cone voltage $(20 / 40 / 60 / 80 / 100 \mathrm{~V})$ were measured to compare the difference in ion response, using the peak areas of seven components (isoquercitrin, isorhamnetin-3-Oglucoside, sinapoyl-9-sucrosecoside, apetalumoside $\mathrm{C} 2$, apetalumoside $\mathrm{B} 10$, apetalumoside $\mathrm{A}$, and epigallocatechin) (Fig. 5). In general, the response of seven index compounds decreased with the increase of capillary voltage. To be specific, four (sinapoyl-9-sucrosecoside, apetalumoside C2, apetalumoside B10 and apetalumoside A) of the seven index compounds were best ionized at the capillary voltage of $1.5 \mathrm{kV}$, while the other three gave the highest ion response at $1.0 \mathrm{kV}$. Hence, we selected the capillary voltage of $1.5 \mathrm{kV}$ as the most appropriate. The changes of cone voltage ranging from 20 to $100 \mathrm{~V}$ led to inconsistent variation trends for the index compounds. Except for apetalumoside A, the response of the other six compounds increased when cone voltage ascended from 20 to $60 \mathrm{~V}$. When the cone voltage 
increased from 80 to $100 \mathrm{~V}$, the response tended to decline. The cone voltage at $60 \mathrm{~V}$ was finally selected in this experiment (Fig. 5). Advanced mass spectrometers can enable slope collision energy or mixed collision energy, which greatly enhanche the quality of the $\mathrm{MS}^{2}$ spectra producing more rich product ions [1,9]. RCE was optimized at four levels (e.g., $10-30 \mathrm{eV}, 20-40 \mathrm{eV}, 30-50 \mathrm{eV}$, and 40-60 eV) by observing the transitions of five compounds (quercetin 3-O- $\beta$-D-glucose-7- $O-\beta$-D-gentiobioside, isoquercitrin, isorhamnetin-3-O-D-glucoside, gluconapin, and sinapoyl-9-sucrosecoside) from the precursor to the product ions to sufficiently fragment different classes of chemical compounds in SDS (Fig. S2). Accordingly, RCE at $20-40 \mathrm{eV}$ was selected, under which rich fragments were obtained for the SDS components.

\section{Conclusions}

In conclusion, the developed UHPLC/IM-QTOF-HDMS ${ }^{\mathrm{E}}$ approach combined with automatic peak annotation workflows of UNIFI enable the characterization of 53 compounds from the seeds of D. sophia, demonstrating a great improvement compared with the literature [14]. Computational data processing-based structural elucidation was very efficient giving reproducible characterization results independent of the professional knowledge in this field. Four dimensions of structure information could be generated by this integral approach, which could improve the reliability in identifying isomers if a CCS comparison is available. The results obtained would greatly benefit the quality control of this herbal medicine.

Acknowledgement: We thank the anonymous reviewers for their helpful comments.

Author Contribution: Simiao Wang, Xue Li, Boxue Chen, Shitong Li, and Jiali Wang performed the experiment and analyzed the experimental data. Jing Wang and Wenzhi Yang designed the research. Simiao Wang, Mingshuo Yang, and Wenzhi Yang drafted the manuscript. Xiaoyan Xu and Hongda Wang polished the manuscript.

Funding Statement: This work was financially supported by the National Key Research and Development Program of China (Grant No. 2018YFC1704500), Tianjin Committee of Science and Technology of China (Grant No. 21ZYJDJC00080), and National Natural Science Foundation of China (Grant No. 81872996).

Conflicts of Interest: The authors declare that they have no conflicts of interest to report regarding this present study.

\section{References}

1. Qian, Y. X., Li, W. W., Wang, H. M., Hu, W. D., Wang, H. D. et al. (2021). A four-dimensional separation approach by offline 2D-LC/IM-TOF-MS in combination with database-driven computational peak annotation facilitating the in-depth characterization of the multicomponents from Atractylodis Macrocephalae Rhizoma (Atractylodes macrocephala). Arabian Journal of Chemistry, 14(2), 102957. DOI 10.1016/j.arabjc.2020.102957.

2. Luo, L., Jiang, J. W., Wang, C., Fitzgerald, M., Hu, W. F. et al. (2020). Analysis on herbal medicines utilized for treatment of COVID-19. Acta Pharmaceutica Sinica B, 10(7), 1192-1204. DOI 10.1016/j.apsb.2020.05.007.

3. Yang, W. Z., Zhang, Y. B., Wu, W. Y., Huang, L. Q., Guo, D. A. et al. (2017). Approaches to establish Q-markers for the quality standards of traditional Chinese medicines. Acta Pharmaceutica Sinica B, 7(4), 439-446. DOI 10.1016/j.apsb.2017.04.012.

4. Wang, S. M., Qian, Y. X., Sun, M. X., Jia, L., Hu, Y. et al. (2020). Holistic quality evaluation of Saposhnikoviae Radix (Saposhnikovia divaricata) by reversed-phase ultra-high performance liquid chromatography and hydrophilic interaction chromatography coupled with ion mobility quadrupole time-of-flight mass spectrometry-based untargeted metabolomics. Arabian Journal of Chemistry, 13(12), 8835-8847. DOI 10.1016/ j.arabjc.2020.10.013. 
5. Qiu, S., Yang, W. Z., Shi, X. J., Yao, C. L., Yang, M. et al. (2015). A green protocol for efficient discovery of novel natural compounds: Characterization of new ginsenosides from the stems and leaves of Panax ginseng as a case study. Analytica Chimica Acta, 893, 65-76. DOI 10.1016/j.aca.2015.08.048.

6. Turgumbayeva, A., Ustenova, G., Datkhayev, U., Rahimov, K., Stankevicius, E. (2019). Safflower (Carthamus tinctorius L.) a potential source of drugs against cryptococcal infections, malaria and leishmaniasis. PhytonInternational Journal of Experimental Botany, 88(3), 137-146. DOI 10.32604/phyton.2020.07665.

7. Yang, W. Z., Ye, G., Meng, A. H., Sabir, G., Qiao, X. et al. (2013). Rapid characterisation of flavonoids from Sophora alopecuroides L. by HPLC/DAD/ESI-MS ${ }^{\mathrm{n}}$. Natural Product Research, 27(4-5), 323-330. DOI 10.1080/14786419.2012.688052.

8. Yang, W. Z., Shi, X. J., Yao, C. L., Huang, Y., Hou, J. J. et al. (2020). A novel neutral loss/product ion scanincorporated integral approach for the untargeted characterization and comparison of the carboxyl-free ginsenosides from Panax ginseng, Panax quinquefolius, and Panax notoginseng. Journal of Pharmaceutical and Biomedical Analysis, 177, 112813. DOI 10.1016/j.jpba.2019.112813.

9. Fu, L. L., Ding, H., Han, L. F., Jia, L., Yang, W. Z. et al. (2019). Simultaneously targeted and untargeted multicomponent characterization of Erzhi Pill by offline two-dimensional liquid chromatography/quadrupoleOrbitrap mass spectrometry. Journal of Chromatography A, 1584, 87-96. DOI 10.1016/j.chroma.2018.11.024.

10. Feng, K. Y., Wang, S. M., Han, L. F., Qian, Y. X., Li, H. F. et al. (2021). Configuration of the ion exchange chromatography, hydrophilic interaction chromatography, and reversed-phase chromatography as off-line threedimensional chromatography coupled with high-resolution quadrupole-orbitrap mass spectrometry for the multicomponent characterization of Uncaria sessilifructus. Journal of Chromatography A, 1649, 462237. DOI 10.1016/j.chroma.2021.462237.

11. Tu, J., Zhou, Z. W., Li, T. Z., Zhu, Z. J. (2019). The emerging role of ion mobility-mass spectrometry in lipidomics to facilitate lipid separation and identification. TrAC Trends in Analytical Chemistry, 116(Suppl. 50), 332-339. DOI 10.1016/j.trac.2019.03.017.

12. Zhou, Z. W., Tu, J., Xiong, X., Shen, X. T., Zhu, Z. J. (2017). LipidCCS: Prediction of collision cross-section values for lipids with high precision to support ion mobility-mass spectrometry-based lipidomics. Analytical Chemistry, 89(17), 9559-9566. DOI 10.1021/acs.analchem.7b02625.

13. Shi, P. P., Chao, L. P., Wang, T. X., Liu, E. W., Han, L. F. et al. (2015). New bioactive flavonoid glycosides isolated from the seeds of Lepidium apetalum Willd. Fitoterapia, 103, 197-205. DOI 10.1016/j.fitote.2015.04.007.

14. Meng, Z. H., Qiao, L., Wang, Z. Q., Ma, Z. S., Jia, J. M. et al. (2015). Analysis of the constituents in Semen descurainiae by UPLC/Q-TOF-MS/MS. Journal of Chinese Pharmaceutical Sciences, 24(5), 303-309. DOI $10.5246 /$ jcps.2015.05.039.

15. Committee of National Pharmacopoeia (2020). China pharmacopoeia (Part 1). Beijing: Chemical Industry Press.

16. Li, M., Zeng, M. N., Zhang, Z. G., Zhang, J. K., Zhang, X. K. et al. (2019). Chemical constituents from the seeds of Lepidium apetalum. Chinese Traditional Patent Medicine, 41(1), 115-110. DOI 10.3969/j.issn.10011528.2019.01.022.

17. Sun, K., Li, X. (2002). Progress in studies on chemical constituents and pharmacological effect of Semen lepidii and Semen descurainiae. Chinese Traditional and Herbal Drugs, 33(7), 100-102. DOI 10.7501/j.issn.02532670.2002.7.341.

18. Guo, W. T., Xing, S. H., Chen, Y., Yi, J. H., Zhang, Y. N. et al. (2018). Research progress of Semen lepidii and its herbal compound on ascites. Chinese Medicine Modern Distance Education of China, 16(6), 157-159. DOI 10.3969/j.issn.1672-2779.2018.06.064.

19. Sun, K., Li, X., Liu, J. M., Wang, J. H., Li, W. et al. (2005). A novel sulphur glycoside from the seeds of Descurainia sophia (L.). Journal of Asian Natural Products Research, 7(6), 853-856. DOI 10.1080/ 1028602042000204072.

20. Wang, A. Q., Wang, X. K., Li, J. L., Cui, X. Y. (2004). Isolation and structure identification of chemical constituents from the seeds of Descurainia sophia L. Webb ex Prantl. Acta Pharmaceutica Sinica, 39(1), 4651. DOI 10.16438/j.0513-4870.2004.01.011. 
21. Chen, D., Liu, X., Yang, X. H., Sun, K. (2010). Study on chemical constituents of Descurainia sophia (L.) Webb ex Prantl. Special Wild Economic Animal and Plant Research, 32(2), 62-63. DOI 10.16720/j.cnki. tcyj.2010.02.022.

22. Li, J. R., Huang, W. H., Guo, B. L., Chen, A. J. (2010). Research on chemical content standard of Semen descurainiae. Chinese Journal of Pharmaceutical Analysis, 30(5), 950-953. DOI 10.16155/j.02541793.2010.05.009.

23. Wang, W. P., Wu, H. M., Liu, M. T., Xu, Y. C., Yin, X. B. et al. (2020). Stability study of quercetin-3-O- $\beta$-Dglucose-7-O- $\beta$-D-diglycoside in Descurainia sophia seeds. China Journal of Traditional Chinese Medicine and Pharmacy, 35(11), 5739-5742.

24. Zhang, C. X., Zuo, T. T., Wang, X. Y., Wang, H. D., Hu, Y. et al. (2019). Integration of data-dependent acquisition (DDA) and data-independent high-definition $\mathrm{MS}^{\mathrm{E}}\left(\mathrm{HDMS}^{\mathrm{E}}\right)$ for the comprehensive profiling and characterization of multicomponents from Panax japonicus by UHPLC/IM-QTOF-MS. Molecules, 24(15), 2708. DOI 10.3390/ molecules24152708.

25. Zuo, T. T., Qian, Y. X., Zhang, C. X., Wei, Y. X., Wang, X. Y. et al. (2019). Data-dependent acquisition and database-driven efficient peak annotation for the comprehensive profiling and characterization of the multicomponents from compound Xueshuantong capsule by UHPLC/IM-QTOF-MS. Molecules, 24 (19), 3431. DOI 10.3390/molecules24193431.

26. Paglia, G., Angel, P., Williams, J. P., Richardson, K., Olivos, H. J. et al. (2015). Ion mobility-derived collision cross section as an additional measure for lipid fingerprinting and identification. Analytical Chemistry, 87(2), 11371144. DOI $10.1021 / \operatorname{ac} 503715 \mathrm{v}$.

27. Jia, L., Zuo, T. T., Zhang, C. X., Li, W. W., Wang, H. D. et al. (2019). Simultaneous profiling and holistic comparison of the metabolomes among the flower buds of Panax ginseng, Panax quinquefolius, and Panax notoginseng by UHPLC/IM-QTOF-HDMS ${ }^{\mathrm{E}}$-based metabolomics analysis. Molecules, 24(11), 2188. DOI 10.3390/molecules24112188.

28. Yang, W. Z., Qiao, X., Bo, T., Wang, Q., Guo, D. A. et al. (2014). Low energy induced homolytic fragmentation of flavonol 3-O-glycoside by negative electrospray ionization tandem mass spectrometry. Rapid Communications in Mass Spectrometry, 28(4), 385-395. DOI 10.1002/rcm.6794.

29. Chen, J. M., Guan, R. Z. (2006). Extraction and identification of several glucosinolates in Descurainia sophia seeds. Acta Botanica Boreali-Occidentalia Sinica, 4(6), 1231-1235. DOI 10.3321/j.issn:1000-4025.2006.06.023. 


\section{Supporting Information}
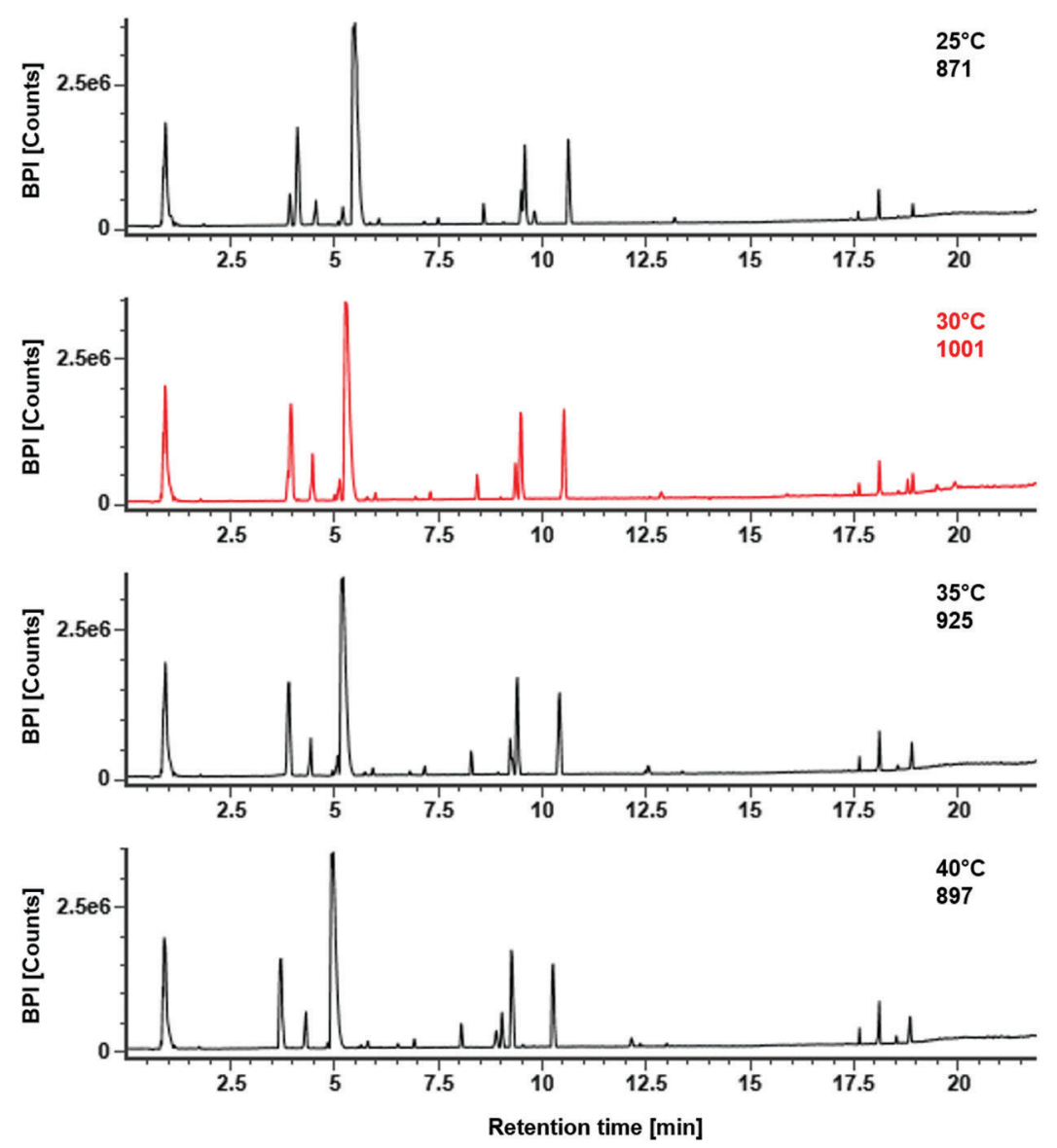

Figure S1: Comparison of column temperature (CSH C18 column) in ESI-mode for separating the multicomponents from the seeds of Descurainia sophia (SDS) 
$\checkmark$ quercetin 3-O- $\beta$-D-glucose-7-O- $\beta$-D-gentiobioside
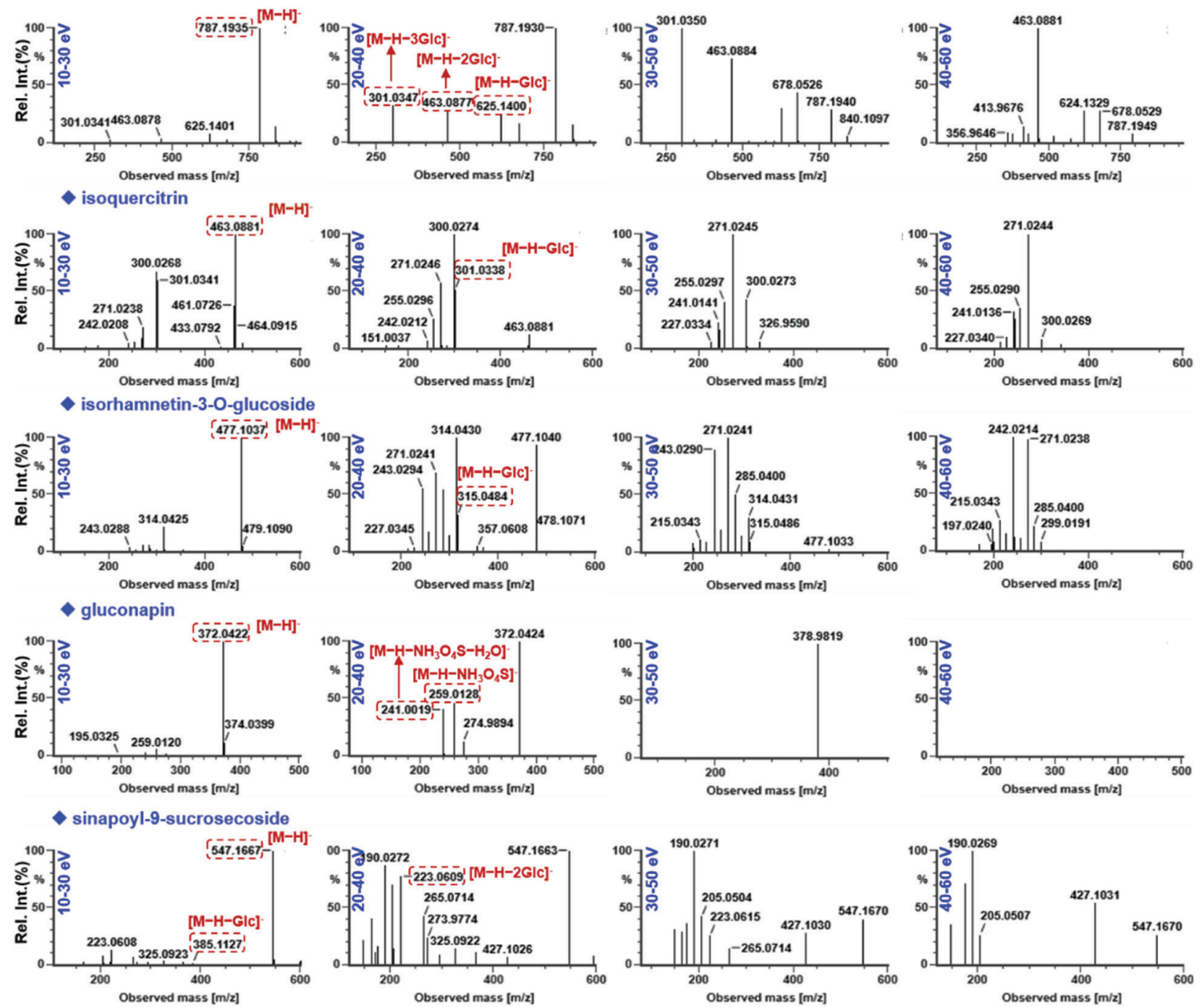

Figure S2: Optimization of the ramp collision energy (RCE) for $\mathrm{HDMS}^{\mathrm{E}}$ using five representative compounds

Table S1: The in-house library of Semon lepidii and Semon descurainiae

\begin{tabular}{|c|c|c|c|}
\hline No. & Name & Formula & Subclass \\
\hline 1 & 2-hydroxy-3-(1H-indol-3-yl) propanoic acid & $\mathrm{C}_{11} \mathrm{H}_{11} \mathrm{NO}_{3}$ & Alkaloid \\
\hline 2 & 2-hydroxyl-3-(1H-indol-3-yl) propanoic acid methyl ester & $\mathrm{C}_{12} \mathrm{H}_{13} \mathrm{NO}_{3}$ & \\
\hline 3 & 3,5-dihydroxy-4-methoxy-benzoic acid & $\mathrm{C}_{8} \mathrm{H}_{8} \mathrm{O}_{5}$ & Benzoic acid \\
\hline 4 & $\begin{array}{l}\text { 1,2-benzenedicarboxylic acid-1,2-bis[2-(2-hydroxyethoxy) } \\
\text { ethyl]ester }\end{array}$ & $\mathrm{C}_{7} \mathrm{H}_{6} \mathrm{O}_{3}$ & \\
\hline 5 & strophanthidine & $\mathrm{C}_{23} \mathrm{H}_{32} \mathrm{O}_{6}$ & Cardiac glycoside \\
\hline 6 & evomonoside & $\mathrm{C}_{29} \mathrm{H}_{44} \mathrm{O}_{8}$ & \\
\hline 7 & $\begin{array}{l}3 \beta, 14 \beta \text {-hydroxy- } 5 \beta \text {-19-oxo-card-20(22)-enolide-3- } O-\beta \text {-D- } \\
\text { glucopyranosyl- }(1 \rightarrow 4)-\beta \text {-D-digitoxose }\end{array}$ & $\mathrm{C}_{35} \mathrm{H}_{52} \mathrm{O}_{13}$ & \\
\hline
\end{tabular}




\section{Table S1 (continued).}

\begin{tabular}{|c|c|c|c|}
\hline No. & Name & Formula & Subclass \\
\hline 8 & apetalumoside $\mathrm{A} 1$ & $\mathrm{C}_{56} \mathrm{H}_{62} \mathrm{O}_{30}$ & Flavonoid \\
\hline 9 & apetalumoside B8 & $\mathrm{C}_{44} \mathrm{H}_{50} \mathrm{O}_{26}$ & \\
\hline 10 & apetalumoside B9 & $\mathrm{C}_{55} \mathrm{H}_{60} \mathrm{O}_{30}$ & \\
\hline 11 & apetalumoside B10 & $\mathrm{C}_{44} \mathrm{H}_{50} \mathrm{O}_{26}$ & \\
\hline 12 & apetalumoside B11 & $\mathrm{C}_{50} \mathrm{H}_{60} \mathrm{O}_{31}$ & \\
\hline 13 & apetalumoside B12 & $\mathrm{C}_{61} \mathrm{H}_{70} \mathrm{O}_{35}$ & \\
\hline 14 & apetalumoside $\mathrm{C} 1$ & $\mathrm{C}_{55} \mathrm{H}_{60} \mathrm{O}_{29}$ & \\
\hline 15 & 6-O-[E]-Sinapoyl- $(\alpha$ and $\beta)$-D-glucopyranoside & $\mathrm{C}_{17} \mathrm{H}_{22} \mathrm{O}_{10}$ & \\
\hline 16 & (E)-2-O-sinapoly-D-glucopyranoside isomer & $\mathrm{C}_{17} \mathrm{H}_{22} \mathrm{O}_{10}$ & \\
\hline 17 & kaempferol & $\mathrm{C}_{15} \mathrm{H}_{10} \mathrm{O}_{6}$ & \\
\hline 18 & isorhamnetin & $\mathrm{C}_{16} \mathrm{H}_{12} \mathrm{O}_{7}$ & \\
\hline 19 & quercetin & $\mathrm{C}_{15} \mathrm{H}_{10} \mathrm{O}_{7}$ & \\
\hline 20 & isorhamnetin-3- $O-\beta$-D-glucopyranoside & $\mathrm{C}_{22} \mathrm{H}_{22} \mathrm{O}_{12}$ & \\
\hline 21 & quercetin-3- $O-\beta$-D-glucopyranoside & $\mathrm{C}_{21} \mathrm{H}_{20} \mathrm{O}_{12}$ & \\
\hline 22 & descurainin A & $\mathrm{C}_{26} \mathrm{H}_{24} \mathrm{O}_{10}$ & \\
\hline 23 & quercetin-3-O- $\beta$-D-glucopyranosyl-7- $O-\beta$-gentiobioside & $\mathrm{C}_{33} \mathrm{H}_{40} \mathrm{O}_{22}$ & \\
\hline 24 & kaempferol-3-O- $\beta$-D-glucopyranosyl-7-O- $\beta$-gentiobioside & $\mathrm{C}_{33} \mathrm{H}_{40} \mathrm{O}_{21}$ & \\
\hline 25 & isorhamnetin-3-O- $\beta$-D-glucopyranosyl-7- $O-\beta$-gentiobioside & $\mathrm{C}_{34} \mathrm{H}_{42} \mathrm{O}_{22}$ & \\
\hline 26 & quercetin-7- $O-\beta$-gentiobioside & $\mathrm{C}_{27} \mathrm{H}_{30} \mathrm{O}_{17}$ & \\
\hline 27 & kaempferol-7-O- $\beta$-gentiobioside & $\mathrm{C}_{27} \mathrm{H}_{30} \mathrm{O}_{16}$ & \\
\hline 28 & $\begin{array}{l}\text { isorhamnetin-7-O- } \beta \text {-gentiobioside/isorhamnetin-3,7-di-O- } \beta \text { - } \\
\text { D-glucopyranosyl }\end{array}$ & $\mathrm{C}_{28} \mathrm{H}_{32} \mathrm{O}_{17}$ & \\
\hline 29 & quercetin-3,7-di- $O-\beta$-D-glucopyranoside & $\mathrm{C}_{27} \mathrm{H}_{30} \mathrm{O}_{17}$ & \\
\hline 30 & kaempferol-3,7-di-O- $\beta$-D-glucopyranoside & $\mathrm{C}_{27} \mathrm{H}_{30} \mathrm{O}_{16}$ & \\
\hline 31 & isorhamnetin-3,7-di- $O$ - $\beta$-D-glucopyranoside & $\mathrm{C}_{28} \mathrm{H}_{32} \mathrm{O}_{17}$ & \\
\hline 32 & $\begin{array}{l}\text { kaempferol-3- } O-\beta \text {-D-glucopyranosyl-7- } O \text { - }[(2-O \text {-trans- } \\
\text { sinnapoyl)- } \beta \text {-D-glucopyranosyl }(1 \rightarrow 6)]-\beta \text {-D-glucopyranoside }\end{array}$ & $\mathrm{C}_{44} \mathrm{H}_{50} \mathrm{O}_{25}$ & \\
\hline 33 & drabanemoroside & $\mathrm{C}_{26} \mathrm{H}_{28} \mathrm{O}_{14}$ & \\
\hline 34 & $\begin{array}{l}\text { quercetin-3-O- } \alpha \text {-L-rhamnopyranosyl- }(1 \rightarrow 2)-\alpha \text {-L- } \\
\text { arabinopyranoside }\end{array}$ & $\mathrm{C}_{26} \mathrm{H}_{28} \mathrm{O}_{15}$ & \\
\hline 35 & $\begin{array}{l}\text { Quercetin-3- } O-\beta-\mathrm{D}-[6-O-\text { sinnapoyl-2- } O-\beta-\mathrm{D}- \\
\text { glucopyranosyl]-glucopyranoside }\end{array}$ & $\mathrm{C}_{38} \mathrm{H}_{40} \mathrm{O}_{21}$ & \\
\hline 36 & $\begin{array}{l}\text { isorhamnetin-3-O-[2-O-(6-O-E-sinapoyl)-B-D- } \\
\text { glucopymosyl]-B-D-glucopyranoside }\end{array}$ & $\mathrm{C}_{39} \mathrm{H}_{42} \mathrm{O}_{21}$ & \\
\hline 37 & quercetin-7-O- $\beta$-D-glucopyranoside & $\mathrm{C}_{21} \mathrm{H}_{20} \mathrm{O}_{12}$ & \\
\hline 38 & isorhamnetin-7- $O-\beta$-D-glucopyranoside & $\mathrm{C}_{22} \mathrm{H}_{22} \mathrm{O}_{12}$ & \\
\hline
\end{tabular}




\section{Table S1 (continued).}

\begin{tabular}{|c|c|c|c|}
\hline No. & Name & Formula & Subclass \\
\hline 39 & kaempferol-7- $O-\beta$-D-glucopyranoside & $\mathrm{C}_{21} \mathrm{H}_{20} \mathrm{O}_{11}$ & \\
\hline 40 & $\begin{array}{l}\text { quercetin-7- } O-\beta \text {-D-glucopyranosyl }(1 \rightarrow 6)-\beta \text {-D- } \\
\text { glucopyranoside }\end{array}$ & $\mathrm{C}_{27} \mathrm{H}_{30} \mathrm{O}_{17}$ & \\
\hline 41 & 4'-O-methyl-dihydroquercetin & $\mathrm{C}_{16} \mathrm{H}_{14} \mathrm{O}_{7}$ & \\
\hline 42 & $\begin{array}{l}\text { kaempferol 3-O- } \alpha \text {-L-arabinopyranoside-7- } O-\alpha \text {-L- } \\
\text { rhamnopyranoside }\end{array}$ & $\mathrm{C}_{26} \mathrm{H}_{28} \mathrm{O}_{14}$ & \\
\hline 43 & apigenin-7- $O-\beta$-D-pyranglycuronide & $\mathrm{C}_{21} \mathrm{H}_{18} \mathrm{O}_{11}$ & \\
\hline 44 & luteolin-7- $O-\beta$-D-glycuronide & $\mathrm{C}_{21} \mathrm{H}_{18} \mathrm{O}_{12}$ & \\
\hline 45 & $(+)-4$ '-O-methylcatechin-7-O- $\beta$-D-glucopyranoside & $\mathrm{C}_{22} \mathrm{H}_{26} \mathrm{O}_{11}$ & \\
\hline 46 & kaempferol-3- $O-\beta$-D-glycuronide & $\mathrm{C}_{21} \mathrm{H}_{18} \mathrm{O}_{12}$ & \\
\hline 47 & kaempferol-3- $O-\beta$-D-glucosyl $(1 \rightarrow 2)-\beta$-D-glucoside & $\mathrm{C}_{27} \mathrm{H}_{30} \mathrm{O}_{16}$ & \\
\hline 48 & kaempferol-3-O- $\beta$-D-glucosyl $(1 \rightarrow 2)-7-\mathrm{O}-\beta$-D-glucoside & $\mathrm{C}_{33} \mathrm{H}_{40} \mathrm{O}_{21}$ & \\
\hline 49 & kaempferol 2G-glucosylgentiobioside & $\mathrm{C}_{33} \mathrm{H}_{40} \mathrm{O}_{21}$ & \\
\hline 50 & quercetin-3-O- $\beta$-D-glucopyranoside & $\mathrm{C}_{21} \mathrm{H}_{18} \mathrm{O}_{13}$ & \\
\hline 51 & quercetin-3-O- $\beta$-D-glucose- $(1 \rightarrow 2)-\beta$-D-glucoside & $\mathrm{C}_{27} \mathrm{H}_{30} \mathrm{O}_{17}$ & \\
\hline 52 & isorhamnetin-3-O-sophoroside & $\mathrm{C}_{28} \mathrm{H}_{32} \mathrm{O}_{17}$ & \\
\hline 53 & $\begin{array}{l}\text { quercetin-3-O-[(6-O-trans-caffeoyl)- } \beta \text {-D-glucopyranosyl]- } \\
\text { 7-O- } \beta \text {-D-glucopyranoside }\end{array}$ & $\mathrm{C}_{42} \mathrm{H}_{46} \mathrm{O}_{25}$ & \\
\hline 54 & apetalumoside A & $\mathrm{C}_{34} \mathrm{H}_{42} \mathrm{O}_{22}$ & \\
\hline 55 & apetalumoside B1 & $\mathrm{C}_{43} \mathrm{H}_{48} \mathrm{O}_{25}$ & \\
\hline 56 & apetalumoside B2 & $\mathrm{C}_{43} \mathrm{H}_{48} \mathrm{O}_{25}$ & \\
\hline 57 & apetalumoside B3 & $\mathrm{C}_{39} \mathrm{H}_{50} \mathrm{O}_{27}$ & \\
\hline 58 & apetalumoside B4 & $\mathrm{C}_{48} \mathrm{H}_{56} \mathrm{O}_{29}$ & \\
\hline 59 & apetalumoside B5 & $\mathrm{C}_{48} \mathrm{H}_{56} \mathrm{O}_{30}$ & \\
\hline 60 & apetalumoside B6 & $\mathrm{C}_{49} \mathrm{H}_{58} \mathrm{O}_{30}$ & \\
\hline 61 & apetalumoside B7 & $\mathrm{C}_{49} \mathrm{H}_{58} \mathrm{O}_{30}$ & \\
\hline 62 & apetalumoside $\mathrm{C}$ & $\mathrm{C}_{48} \mathrm{H}_{56} \mathrm{O}_{29}$ & \\
\hline 63 & $\begin{array}{l}\text { quercetin-3- } O \text {-(2,6-di- } O-\beta \text {-D-glucopyranosyl)- } \beta \text {-D- } \\
\text { glucopyranoside }\end{array}$ & $\mathrm{C}_{33} \mathrm{H}_{40} \mathrm{O}_{22}$ & \\
\hline 64 & isorhamnetin-7-O- $\alpha$-L-rhamnopyranoside & $\mathrm{C}_{22} \mathrm{H}_{22} \mathrm{O}_{11}$ & \\
\hline 65 & apetalumoside $\mathrm{C} 2$ & $\mathrm{C}_{44} \mathrm{H}_{50} \mathrm{O}_{25}$ & \\
\hline 66 & isorhamnetin-3,4'-O- $\beta$-D-diglucoside & $\mathrm{C}_{28} \mathrm{H}_{32} \mathrm{O}_{17}$ & \\
\hline 67 & quercetin-3-O- $\beta$-D-galactopyranoside & $\mathrm{C}_{21} \mathrm{H}_{20} \mathrm{O}_{12}$ & \\
\hline 68 & isorhamnetin-3-O- $\beta$-D-galactopyranoside & $\mathrm{C}_{22} \mathrm{H}_{22} \mathrm{O}_{12}$ & \\
\hline 69 & kaempferol-3-O- $\beta$-D-galactopyranoside & $\mathrm{C}_{21} \mathrm{H}_{20} \mathrm{O}_{11}$ & \\
\hline
\end{tabular}




\section{Table S1 (continued).}

\begin{tabular}{|c|c|c|c|}
\hline No. & Name & Formula & Subclass \\
\hline 70 & $\begin{array}{l}\text { kaempferol-3- } O \text { - } \beta \text {-D-xylopyranosyl }(1 \rightarrow 2)-\beta \text {-D- } \\
\text { glucopyranoside }\end{array}$ & $\mathrm{C}_{26} \mathrm{H}_{28} \mathrm{O}_{15}$ & \\
\hline 71 & kaempferol-3- $O-\beta$-D-glucopyranoside & $\mathrm{C}_{21} \mathrm{H}_{20} \mathrm{O}_{11}$ & \\
\hline 72 & quercetin-3- $O-\beta$-D-arabinopyranoside & $\mathrm{C}_{20} \mathrm{H}_{18} \mathrm{O}_{11}$ & \\
\hline 73 & quercetin-3-O- $\beta$-D-xylopyranoside & $\mathrm{C}_{20} \mathrm{H}_{18} \mathrm{O}_{11}$ & \\
\hline 74 & descurainoside & $\mathrm{C}_{17} \mathrm{H}_{20} \mathrm{O}_{9} \mathrm{~S}$ & Glucoside \\
\hline 75 & gluconapin & $\mathrm{C}_{11} \mathrm{H}_{19} \mathrm{NO}_{9} \mathrm{~S}_{2}$ & \\
\hline 76 & glucoiberverin & $\mathrm{C}_{11} \mathrm{H}_{21} \mathrm{NO}_{9} \mathrm{~S}_{3}$ & \\
\hline 77 & glucotropaeolin & $\mathrm{C}_{14} \mathrm{H}_{19} \mathrm{NO}_{9} \mathrm{~S}_{2}$ & \\
\hline 78 & glucoca-ppasalin & $\mathrm{C}_{15} \mathrm{H}_{27} \mathrm{NO}_{10} \mathrm{~S}_{2}$ & \\
\hline 79 & 3-hydroxy-5-(methylsulfinyl)pentyl & $\mathrm{C}_{13} \mathrm{H}_{25} \mathrm{NO}_{11} \mathrm{~S}_{3}$ & \\
\hline 80 & 3-hydroxy-5-(methylsulfonyl)pentyl & $\mathrm{C}_{13} \mathrm{H}_{25} \mathrm{NO}_{12} \mathrm{~S}_{3}$ & \\
\hline 81 & 3-phenylpropionitrile & $\mathrm{C}_{9} \mathrm{H}_{9} \mathrm{~N}$ & \\
\hline 82 & crotononitrile & $\mathrm{C}_{4} \mathrm{H}_{5} \mathrm{~N}$ & \\
\hline 83 & benzylisothiocyanate & $\mathrm{C}_{8} \mathrm{H}_{7} \mathrm{NS}$ & \\
\hline 84 & allylisothiocyanate & $\mathrm{C}_{4} \mathrm{H}_{5} \mathrm{NS}$ & \\
\hline 85 & butene isothiocyanate & $\mathrm{C}_{5} \mathrm{H}_{7} \mathrm{NS}$ & \\
\hline 86 & 2-phenylethyl isothiocyanate & $\mathrm{C}_{9} \mathrm{H}_{9} \mathrm{NS}$ & \\
\hline 87 & 4-methylthiobutyl isothiocyanate & $\mathrm{C}_{6} \mathrm{H}_{11} \mathrm{NS}_{2}$ & \\
\hline 88 & diallyl disulfide & $\mathrm{C}_{6} \mathrm{H}_{10} \mathrm{~S}_{2}$ & \\
\hline 89 & 1-cyano-3,4-epithiobutane & $\mathrm{C}_{5} \mathrm{H}_{7} \mathrm{NS}$ & \\
\hline 90 & 5-methylthiopentanitrile & $\mathrm{C}_{6} \mathrm{H}_{11} \mathrm{NS}$ & \\
\hline 91 & 1,3-di- $O$-sinapoyl- $\beta$-D-glucopyranoside & $\mathrm{C}_{28} \mathrm{H}_{32} \mathrm{O}_{14}$ & \\
\hline 92 & 1,2-di- $O$-sinapoyl- $\beta$-D-glucopyranoside & $\mathrm{C}_{28} \mathrm{H}_{32} \mathrm{O}_{14}$ & \\
\hline 93 & 1,2-disinapoylgentiobiose & $\mathrm{C}_{33} \mathrm{H}_{40} \mathrm{O}_{19}$ & \\
\hline 94 & helveticoside & $\mathrm{C}_{29} \mathrm{H}_{42} \mathrm{O}_{9}$ & \\
\hline 95 & evobioside & $\mathrm{C}_{36} \mathrm{H}_{56} \mathrm{O}_{12}$ & \\
\hline 96 & erysimoside & $\mathrm{C}_{35} \mathrm{H}_{52} \mathrm{O}_{14}$ & \\
\hline 97 & raphanuside $\mathrm{C}$ & $\mathrm{C}_{18} \mathrm{H}_{24} \mathrm{O}_{10} \mathrm{~S}$ & \\
\hline 98 & apetalumoside D & $\mathrm{C}_{22} \mathrm{H}_{34} \mathrm{O}_{13} \mathrm{~S}_{2}$ & \\
\hline 99 & $\begin{array}{l}\text { 1-thio- } \beta \text {-D-glucopyranosyl }(1 \rightarrow 1)-1 \text {-thio- } \alpha \text {-D- } \\
\text { glucopyranoside astragalin }\end{array}$ & $\mathrm{C}_{12} \mathrm{H}_{22} \mathrm{O}_{10} \mathrm{~S}_{2}$ & \\
\hline 100 & raphanuside & $\mathrm{C}_{16} \mathrm{H}_{22} \mathrm{O}_{8} \mathrm{~S}$ & \\
\hline 101 & raphanuside $\mathrm{B}$ & $\mathrm{C}_{16} \mathrm{H}_{22} \mathrm{O}_{8} \mathrm{~S}$ & \\
\hline 102 & raphanuside D & $\mathrm{C}_{16} \mathrm{H}_{22} \mathrm{O}_{9} \mathrm{~S}$ & \\
\hline
\end{tabular}




\section{Table S1 (continued).}

\begin{tabular}{|c|c|c|c|}
\hline No. & Name & Formula & Subclass \\
\hline 103 & glucosinalbin & $\mathrm{C}_{14} \mathrm{H}_{19} \mathrm{NO}_{10} \mathrm{~S}_{2}$ & \\
\hline 104 & sinigrin & $\mathrm{C}_{10} \mathrm{H}_{16} \mathrm{KNO}_{9} \mathrm{~S}_{2}$ & \\
\hline 105 & 2-phenylethy-1- $O-\beta$-D-glucopyranoside & $\mathrm{C}_{13} \mathrm{H}_{18} \mathrm{O}_{6}$ & \\
\hline 106 & 4-hydroxybenzyl cyanide & $\mathrm{C}_{14} \mathrm{H}_{20} \mathrm{O}_{6}$ & \\
\hline 107 & trilobatin & $\mathrm{C}_{21} \mathrm{H}_{24} \mathrm{O}_{10}$ & \\
\hline 108 & phloretin-2',4'-di- $O-\beta$-D-glucopyranoside & $\mathrm{C}_{27} \mathrm{H}_{34} \mathrm{O}_{15}$ & \\
\hline 109 & lepidiumlignan $\mathrm{A}$ & $\mathrm{C}_{22} \mathrm{H}_{26} \mathrm{O}_{9}$ & Lignin \\
\hline 110 & lepidiumlignan B & $\mathrm{C}_{20} \mathrm{H}_{20} \mathrm{O}_{7}$ & \\
\hline 111 & $\begin{array}{l}\text { erythro-1-(4-O- } \beta \text {-D-glucopyranosyl-3-methoxyphenyl)-2- } \\
\text { [4-(3-hydroxypropyl)-2,6-dimethoxyphenoxy]-1,3- } \\
\text { propanediol }\end{array}$ & $\mathrm{C}_{27} \mathrm{H}_{38} \mathrm{O}_{13}$ & \\
\hline 112 & $\begin{array}{l}\text { (7R,7'E,8S)-4,9-dihydroxy-3,3',5-trimethoxy-4',7-epoxy- } \\
\text { 8,5'-neolign-7'-en-9'-oic acid }\end{array}$ & $\mathrm{C}_{21} \mathrm{H}_{22} \mathrm{O}_{8}$ & \\
\hline 113 & spicatolignan B & $\mathrm{C}_{20} \mathrm{H}_{20} \mathrm{O}_{7}$ & \\
\hline 114 & pinoresinol 4- $O-\beta$-D-glucopyranoside & $\mathrm{C}_{26} \mathrm{H}_{32} \mathrm{O}_{11}$ & \\
\hline 115 & $(+)$-isolariciresinol & $\mathrm{C}_{20} \mathrm{H}_{24} \mathrm{O}_{6}$ & \\
\hline 116 & syringaresin-4'- $O-\beta$-D-monoglucoside & $\mathrm{C}_{28} \mathrm{H}_{36} \mathrm{O}_{13}$ & \\
\hline 117 & $\begin{array}{l}\text { dimethyl(E,E)-4,4'-dihydroxy-3,3',5,5'-tetramethoxylign- } \\
\text { 7,7'-dien-9,9'-dioate }\end{array}$ & $\mathrm{C}_{24} \mathrm{H}_{26} \mathrm{O}_{10}$ & \\
\hline 118 & isovanillic acid & $\mathrm{C}_{8} \mathrm{H}_{8} \mathrm{O}_{4}$ & Organic acid \\
\hline 119 & syringic acid & $\mathrm{C}_{9} \mathrm{H}_{10} \mathrm{O}_{5}$ & \\
\hline 120 & p-hydroxy benzoic acid & $\mathrm{C}_{7} \mathrm{H}_{6} \mathrm{O}_{3}$ & \\
\hline 121 & p-hydroxy benzaldehyde & $\mathrm{C}_{7} \mathrm{H}_{6} \mathrm{O}_{2}$ & \\
\hline 122 & nicotinic acid & $\mathrm{C}_{6} \mathrm{H}_{5} \mathrm{NO}_{2}$ & \\
\hline 123 & descurainoside $\mathrm{B}$ & $\mathrm{C}_{19} \mathrm{H}_{26} \mathrm{O}_{10}$ & \\
\hline 124 & sinapic acid & $\mathrm{C}_{11} \mathrm{H}_{12} \mathrm{O}_{5}$ & \\
\hline 125 & syringaldehyde & $\mathrm{C}_{9} \mathrm{H}_{10} \mathrm{O}_{4}$ & \\
\hline 126 & 3,4,5-trimethoxycinnamic acid & $\mathrm{C}_{12} \mathrm{H}_{14} \mathrm{O}_{5}$ & \\
\hline 127 & sinapic acid ethyl ester & $\mathrm{C}_{13} \mathrm{H}_{16} \mathrm{O}_{5}$ & \\
\hline 128 & 4-pentenamide & $\mathrm{C}_{5} \mathrm{H}_{9} \mathrm{NO}$ & Others \\
\hline 129 & 5-hydroxymethyl furfural & $\mathrm{C}_{6} \mathrm{H}_{6} \mathrm{O}_{3}$ & \\
\hline 130 & 2,5-Dimethyl-7-hydroxy chromone & $\mathrm{C}_{11} \mathrm{H}_{10} \mathrm{O}_{3}$ & \\
\hline 131 & $\beta$-sitosterol & $\mathrm{C}_{29} \mathrm{H}_{50} \mathrm{O}$ & \\
\hline 132 & $\beta$-Amyrin & $\mathrm{C}_{30} \mathrm{H}_{50} \mathrm{O}$ & \\
\hline 133 & cholesterol & $\mathrm{C}_{27} \mathrm{H}_{46} \mathrm{O}$ & \\
\hline 134 & eleutheroside A & $\mathrm{C}_{35} \mathrm{H}_{60} \mathrm{O}_{6}$ & \\
\hline
\end{tabular}




\begin{tabular}{|c|c|c|c|}
\hline No. & Name & Formula & Subclass \\
\hline 135 & sinapine bisulfate & $\mathrm{C}_{16} \mathrm{H}_{25} \mathrm{NO}_{9} \mathrm{~S}$ & \\
\hline 136 & uracil & $\mathrm{C}_{4} \mathrm{H}_{4} \mathrm{~N}_{2} \mathrm{O}_{2}$ & \\
\hline 137 & thymine & $\mathrm{C}_{5} \mathrm{H}_{6} \mathrm{~N}_{2} \mathrm{O}_{2}$ & \\
\hline 138 & 3-methoxyinositol & $\mathrm{C}_{7} \mathrm{H}_{14} \mathrm{O}_{6}$ & \\
\hline 139 & aurantiamide acetate & $\mathrm{C}_{27} \mathrm{H}_{28} \mathrm{~N}_{2} \mathrm{O}_{4}$ & \\
\hline 140 & uridine & $\mathrm{C}_{9} \mathrm{H}_{12} \mathrm{~N}_{2} \mathrm{O}_{6}$ & \\
\hline 141 & thymidine & $\mathrm{C}_{10} \mathrm{H}_{14} \mathrm{~N}_{2} \mathrm{O}_{5}$ & \\
\hline 142 & tormentic acid & $\mathrm{C}_{30} \mathrm{H}_{48} \mathrm{O}_{5}$ & \\
\hline 143 & glycerol & $\mathrm{C}_{3} \mathrm{H}_{8} \mathrm{O}_{3}$ & \\
\hline 144 & lepidiumuridine A & $\mathrm{C}_{15} \mathrm{H}_{22} \mathrm{~N}_{2} \mathrm{O}_{11}$ & \\
\hline 145 & methyl-5-hydroxypyridine-2-carboxlate & $\mathrm{C}_{7} \mathrm{H}_{7} \mathrm{NO}_{3}$ & \\
\hline 146 & benzylcarbamic acid & $\mathrm{C}_{8} \mathrm{H}_{9} \mathrm{NO}_{2}$ & \\
\hline 147 & $N$-benzylformamide & $\mathrm{C}_{8} \mathrm{H}_{9} \mathrm{NO}$ & \\
\hline 148 & 1-phenyl-1,2-ethanediol & $\mathrm{C}_{8} \mathrm{H}_{10} \mathrm{O}_{2}$ & \\
\hline 149 & methyl-2,4,6-trihydroxybenzoate & $\mathrm{C}_{8} \mathrm{H}_{8} \mathrm{O}_{5}$ & \\
\hline 150 & 2-(4-hydroxyphenyl) acetonitrile & $\mathrm{C}_{8} \mathrm{H}_{7} \mathrm{NO}$ & \\
\hline 151 & 3-tert-butyl isothioisocyanate & $\mathrm{C}_{5} \mathrm{H}_{9} \mathrm{NS}$ & \\
\hline 152 & 3,4-Dihydroxybenzoic acid & $\mathrm{C}_{7} \mathrm{H}_{6} \mathrm{O}_{4}$ & \\
\hline 153 & antithiamine factor & $\mathrm{C}_{12} \mathrm{H}_{14} \mathrm{O}_{5}$ & \\
\hline 154 & 2-hexadecenoic acid & $\mathrm{C}_{16} \mathrm{H}_{30} \mathrm{O}_{2}$ & \\
\hline 155 & behenic acid & $\mathrm{C}_{22} \mathrm{H}_{44} \mathrm{O}_{2}$ & \\
\hline 156 & $\begin{array}{l}\text { 2-O-(3,4-dihydroxybenzoyl)-2,4,6-trihydroxy phenylacetic } \\
\text { acid 4-O- } \beta \text {-D-glucopyranoside }\end{array}$ & $\mathrm{C}_{21} \mathrm{H}_{22} \mathrm{O}_{13}$ & \\
\hline 157 & 4,9 -di- $O$ - $\beta$-D-glucosyl sinapoyl alcohol & $\mathrm{C}_{23} \mathrm{H}_{34} \mathrm{O}_{14}$ & \\
\hline 158 & 3',5'-dimethoxy-4- $O-\beta$-D-glucopyranosyl cinnamic acid & $\mathrm{C}_{17} \mathrm{H}_{22} \mathrm{O}_{10}$ & \\
\hline 159 & sinapoylglucose & $\mathrm{C}_{17} \mathrm{H}_{22} \mathrm{O}_{10}$ & \\
\hline 160 & sinapoyl-9-sucrosecoside & $\mathrm{C}_{23} \mathrm{H}_{32} \mathrm{O}_{15}$ & \\
\hline 161 & lariciresinol 4'-O- $\beta$-D-glucopyranoside & $\mathrm{C}_{26} \mathrm{H}_{34} \mathrm{O}_{11}$ & \\
\hline 162 & (7S,8R)-aegineoside & $\mathrm{C}_{26} \mathrm{H}_{30} \mathrm{O}_{12}$ & \\
\hline 163 & $L$-tryptophan & $\mathrm{C}_{11} \mathrm{H}_{12} \mathrm{~N}_{2} \mathrm{O}_{2}$ & \\
\hline 164 & adenosine & $\mathrm{C}_{10} \mathrm{H}_{13} \mathrm{~N}_{5} \mathrm{O}_{4}$ & \\
\hline 165 & stachyose & $\mathrm{C}_{24} \mathrm{H}_{42} \mathrm{O}_{21}$ & \\
\hline 166 & $\begin{array}{l}\text { 1,2-benzenedicarboxylic acid-1,2-bis[2-(2-hydroxyethoxy) } \\
\text { ethyl] ester }\end{array}$ & $\mathrm{C}_{16} \mathrm{H}_{22} \mathrm{O}_{8}$ & \\
\hline 167 & uridine & $\mathrm{C}_{13} \mathrm{H}_{14} \mathrm{~N}_{2} \mathrm{O}_{3}$ & \\
\hline
\end{tabular}




\section{Table S1 (continued).}

\begin{tabular}{|c|c|c|}
\hline No. Name & Formula & Subclass \\
\hline 168 methyl dioxindole 3 -acetate & $\mathrm{C}_{11} \mathrm{H}_{11} \mathrm{NO}_{4}$ & \\
\hline 169 dioxindole-3-acetic acid & $\mathrm{C}_{10} \mathrm{H}_{9} \mathrm{NO}_{4}$ & \\
\hline $170 \operatorname{cyclo}(L-P r o-L-P h e)$ & $\mathrm{C}_{14} \mathrm{H}_{16} \mathrm{~N}_{2} \mathrm{O}_{2}$ & \\
\hline 171 4-amino-4-carboxychroman-2-one & $\mathrm{C}_{10} \mathrm{H}_{9} \mathrm{NO}_{4}$ & \\
\hline 172 sucrose & $\mathrm{C}_{12} \mathrm{H}_{22} \mathrm{O}_{11}$ & \\
\hline 173 (S)-p-hydroxyphenyl lactate acid & $\mathrm{C}_{9} \mathrm{H}_{10} \mathrm{O}_{4}$ & \\
\hline 174 (S)-2-hydroxy-phenylpropionic acid & $\mathrm{C}_{9} \mathrm{H}_{10} \mathrm{O}_{3}$ & \\
\hline 175 linolenic acid & $\mathrm{C}_{18} \mathrm{H}_{30} \mathrm{O}_{2}$ & \\
\hline 176 linolic acid & $\mathrm{C}_{18} \mathrm{H}_{32} \mathrm{O}_{2}$ & \\
\hline 177 palmitic acid & $\mathrm{C}_{16} \mathrm{H}_{32} \mathrm{O}_{2}$ & \\
\hline 178 oleic acid & $\mathrm{C}_{18} \mathrm{H}_{34} \mathrm{O}_{2}$ & \\
\hline 179 myristic acid & $\mathrm{C}_{14} \mathrm{H}_{28} \mathrm{O}_{2}$ & \\
\hline 180 stearic acid & $\mathrm{C}_{18} \mathrm{H}_{36} \mathrm{O}_{2}$ & \\
\hline 181 arachidic acid & $\mathrm{C}_{20} \mathrm{H}_{40} \mathrm{O}_{2}$ & \\
\hline 182 eicosenoic acid & $\mathrm{C}_{20} \mathrm{H}_{38} \mathrm{O}_{2}$ & \\
\hline 183 sinapine & $\mathrm{C}_{16} \mathrm{H}_{24} \mathrm{NO}_{5}^{+}$ & \\
\hline $184(13 Z, 16 Z)$-docosadienoic acid & $\mathrm{C}_{22} \mathrm{H}_{40} \mathrm{O}_{2}$ & \\
\hline 185 cis-11,14,17-eicosatrienoic acid & $\mathrm{C}_{20} \mathrm{H}_{34} \mathrm{O}_{2}$ & \\
\hline 186 erucic acid & $\mathrm{C}_{22} \mathrm{H}_{42} \mathrm{O}_{2}$ & \\
\hline 187 protocatechuic aldehyde & $\mathrm{C}_{7} \mathrm{H}_{6} \mathrm{O}_{3}$ & Phenolic \\
\hline 188 2-(4-hydroxy-phenyl)-ethanol & $\mathrm{C}_{8} \mathrm{H}_{10} \mathrm{O}_{2}$ & \\
\hline 189 protocatechuic acid methyl ester & $\mathrm{C}_{8} \mathrm{H}_{8} \mathrm{O}_{4}$ & \\
\hline 190 epigallocatechin & $\mathrm{C}_{15} \mathrm{H}_{14} \mathrm{O}_{7}$ & \\
\hline 191 dimethylthomasidioate & $\mathrm{C}_{24} \mathrm{H}_{26} \mathrm{O}_{10}$ & \\
\hline 192 carbamic acid & $\mathrm{C}_{8} \mathrm{H}_{15} \mathrm{NO}_{3}$ & Phenolic acid \\
\hline 193 acetamide & $\mathrm{C}_{2} \mathrm{H}_{5} \mathrm{NO}$ & \\
\hline 194 2-phenylacetamide & $\mathrm{C}_{8} \mathrm{H}_{9} \mathrm{NO}$ & \\
\hline 195 cis-desulfoglucotropaeolin & $\mathrm{C}_{14} \mathrm{H}_{19} \mathrm{NO}_{6} \mathrm{~S}$ & Phenylacetamide \\
\hline 196 trans-desulfoglucotropaeolin & $\mathrm{C}_{14} \mathrm{H}_{19} \mathrm{NO}_{6} \mathrm{~S}$ & \\
\hline $197 N$-acetyltryptophan & $\mathrm{C}_{8} \mathrm{H}_{7} \mathrm{NO}$ & Phenylacetonitrile \\
\hline $198 N$-benzyl-2-hydroxy-2-phenylacetamide & $\mathrm{C}_{15} \mathrm{H}_{16} \mathrm{~N}_{2} \mathrm{O}$ & Phenylethylamine \\
\hline 199 5-hydroxy-1-phenymethyl-2-pyrrolidinone & $\mathrm{C}_{11} \mathrm{H}_{13} \mathrm{NO}_{2}$ & \\
\hline 200 5-methoxy-1-phenymethyl-2-pyrrolidinone & $\mathrm{C}_{12} \mathrm{H}_{15} \mathrm{NO}_{2}$ & \\
\hline 201 descuraic acid & $\mathrm{C}_{21} \mathrm{H}_{22} \mathrm{O}_{8}$ & Phenylpropanoid \\
\hline 202 descurainolide A & $\mathrm{C}_{13} \mathrm{H}_{16} \mathrm{O}_{5}$ & \\
\hline
\end{tabular}




\section{Table S1 (continued).}

\begin{tabular}{|c|c|c|}
\hline No. Name & Formula & Subclass \\
\hline 203 descurainolide B & $\mathrm{C}_{21} \mathrm{H}_{22} \mathrm{O}_{8}$ & \\
\hline 204 descurainin & $\mathrm{C}_{16} \mathrm{H}_{18} \mathrm{O}_{6}$ & \\
\hline 205 syringaresinol & $\mathrm{C}_{22} \mathrm{H}_{26} \mathrm{O}_{8}$ & \\
\hline 206 scopoletin & $\mathrm{C}_{10} \mathrm{H}_{8} \mathrm{O}_{4}$ & \\
\hline 207 scopoline & $\mathrm{C}_{16} \mathrm{H}_{18} \mathrm{O}_{9}$ & \\
\hline 208 isoscopoletin & $\mathrm{C}_{10} \mathrm{H}_{8} \mathrm{O}_{4}$ & \\
\hline 209 xanthtoxol & $\mathrm{C}_{11} \mathrm{H}_{6} \mathrm{O}_{4}$ & \\
\hline 210 xanthtoxin & $\mathrm{C}_{12} \mathrm{H}_{8} \mathrm{O}_{4}$ & \\
\hline 211 psoralene & $\mathrm{C}_{11} \mathrm{H}_{6} \mathrm{O}_{3}$ & \\
\hline 212 bergaptane & $\mathrm{C}_{12} \mathrm{H}_{8} \mathrm{O}_{4}$ & \\
\hline 213 lanosterol & $\mathrm{C}_{30} \mathrm{H}_{50} \mathrm{O}$ & Steroid \\
\hline 214 descuraic anhydride A & $\mathrm{C}_{20} \mathrm{H}_{21} \mathrm{O}_{7} \mathrm{~N}_{2}^{+}$ & $\begin{array}{l}\text { Tobacco flavor } \\
\text { anhydride }\end{array}$ \\
\hline 215 descuraic anhydride B & $\mathrm{C}_{21} \mathrm{H}_{23} \mathrm{O}_{8} \mathrm{~N}_{2}^{+}$ & \\
\hline 216 descuraic anhydride $\mathrm{C}$ & $\mathrm{C}_{19} \mathrm{H}_{19} \mathrm{~N}_{2} \mathrm{O}_{6}^{+}$ & \\
\hline 217 descuraic cyclolign anhydride A & $\mathrm{C}_{42} \mathrm{H}_{44} \mathrm{O}_{16} \mathrm{~N}_{42}^{+}$ & \\
\hline 218 descuraic cyclolign anhydride B & $\mathrm{C}_{42} \mathrm{H}_{44} \mathrm{O}_{16} \mathrm{~N}_{42}^{+}$ & \\
\hline 219 descuraic cyclolign anhydride C & $\mathrm{C}_{42} \mathrm{H}_{44} \mathrm{O}_{16} \mathrm{~N}_{42}^{+}$ & \\
\hline 220 descuraic cyclolign anhyride dimer & $\mathrm{C}_{66} \mathrm{H}_{68} \mathrm{~N}_{4} \mathrm{O}_{262}^{+}$ & \\
\hline 221 descuraic cyclolign anhydride amide & $\mathrm{C}_{32} \mathrm{H}_{29} \mathrm{~N}_{2} \mathrm{O}_{12}^{+}$ & \\
\hline 222 caulophyllogenin & $\mathrm{C}_{30} \mathrm{H}_{48} \mathrm{O}_{5}$ & Triterpenoid \\
\hline 223 lepidiumuridine $\mathrm{B}$ & $\mathrm{C}_{22} \mathrm{H}_{26} \mathrm{~N}_{2} \mathrm{O}_{13}$ & Uridine derivative \\
\hline 224 lepidiumuridine $\mathrm{C}$ & $\mathrm{C}_{22} \mathrm{H}_{26} \mathrm{~N}_{2} \mathrm{O}_{12}$ & \\
\hline 225 lepidiumuridine $\mathrm{D}$ & $\mathrm{C}_{20} \mathrm{H}_{30} \mathrm{~N}_{2} \mathrm{O}_{12}$ & \\
\hline 226 lepidiumuridine $\mathrm{E}$ & $\mathrm{C}_{20} \mathrm{H}_{30} \mathrm{~N}_{2} \mathrm{O}_{13}$ & \\
\hline 227 lepidiumuridine $\mathrm{F}$ & $\mathrm{C}_{32} \mathrm{H}_{33} \mathrm{~N}_{3} \mathrm{O}_{15}$ & \\
\hline 228 lepidiumuridine $\mathrm{G}$ & $\mathrm{C}_{32} \mathrm{H}_{33} \mathrm{~N}_{3} \mathrm{O}_{15}$ & \\
\hline 229 lepidiumuridine $\mathrm{H}$ & $\mathrm{C}_{22} \mathrm{H}_{31} \mathrm{~N}_{3} \mathrm{O}_{13}$ & \\
\hline 230 lepidiumuridine I & $\mathrm{C}_{25} \mathrm{H}_{29} \mathrm{~N}_{3} \mathrm{O}_{14}$ & \\
\hline 231 lepidiumuridine $\mathrm{J}$ & $\mathrm{C}_{25} \mathrm{H}_{29} \mathrm{~N}_{3} \mathrm{O}_{14}$ & \\
\hline 232 lepidiumuridine $\mathrm{K}$ & $\mathrm{C}_{16} \mathrm{H}_{16} \mathrm{~N}_{2} \mathrm{O}_{7}$ & \\
\hline
\end{tabular}




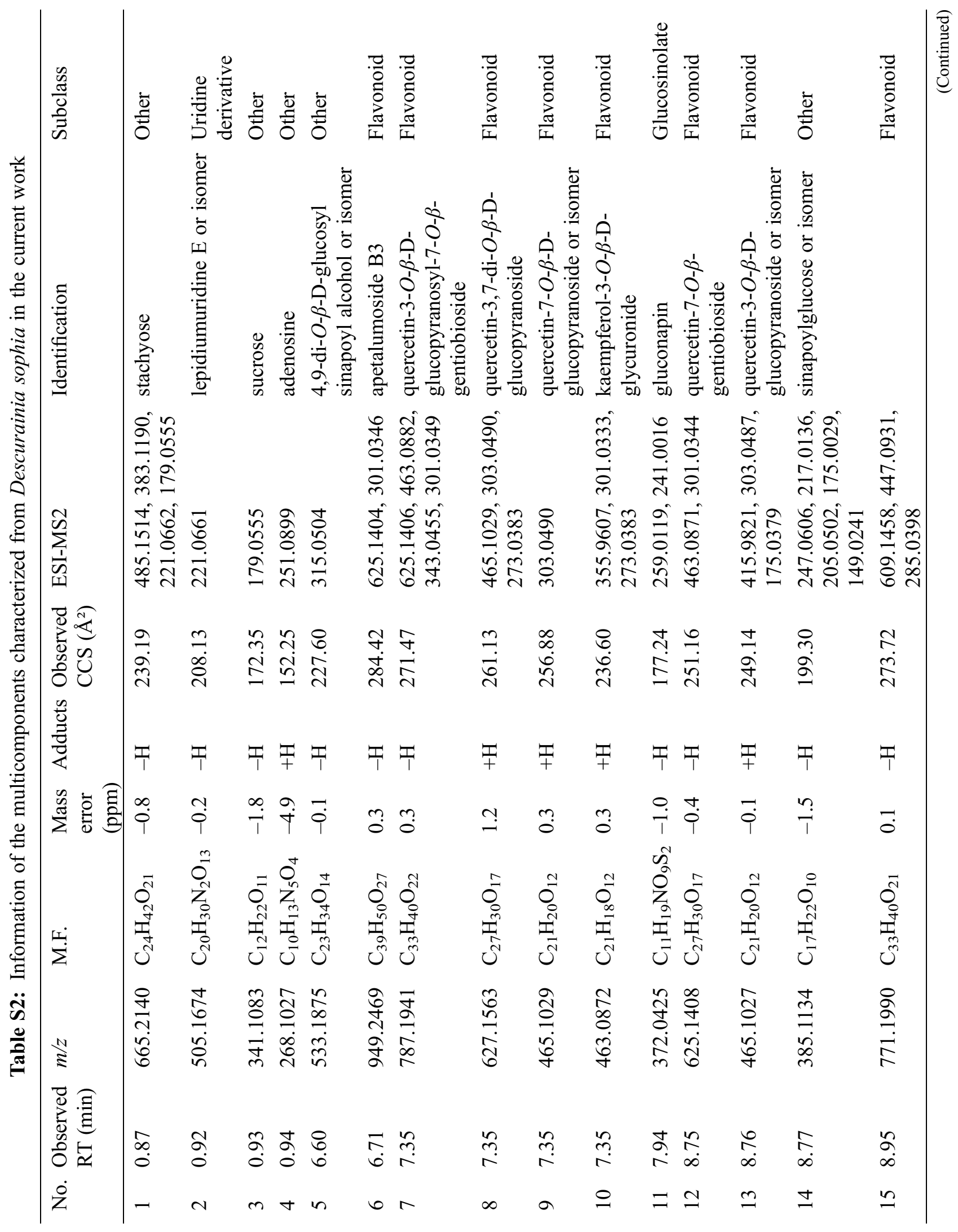




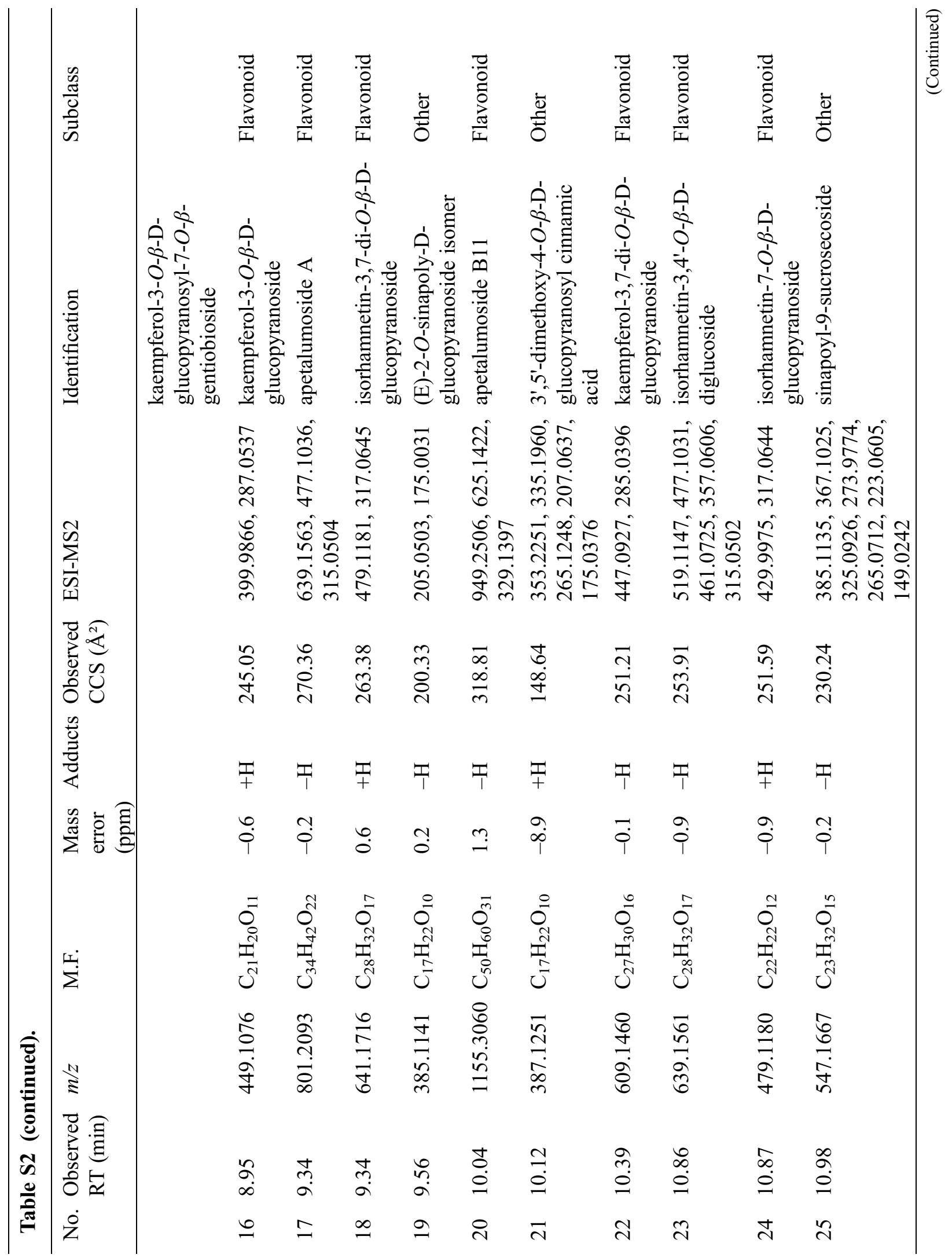




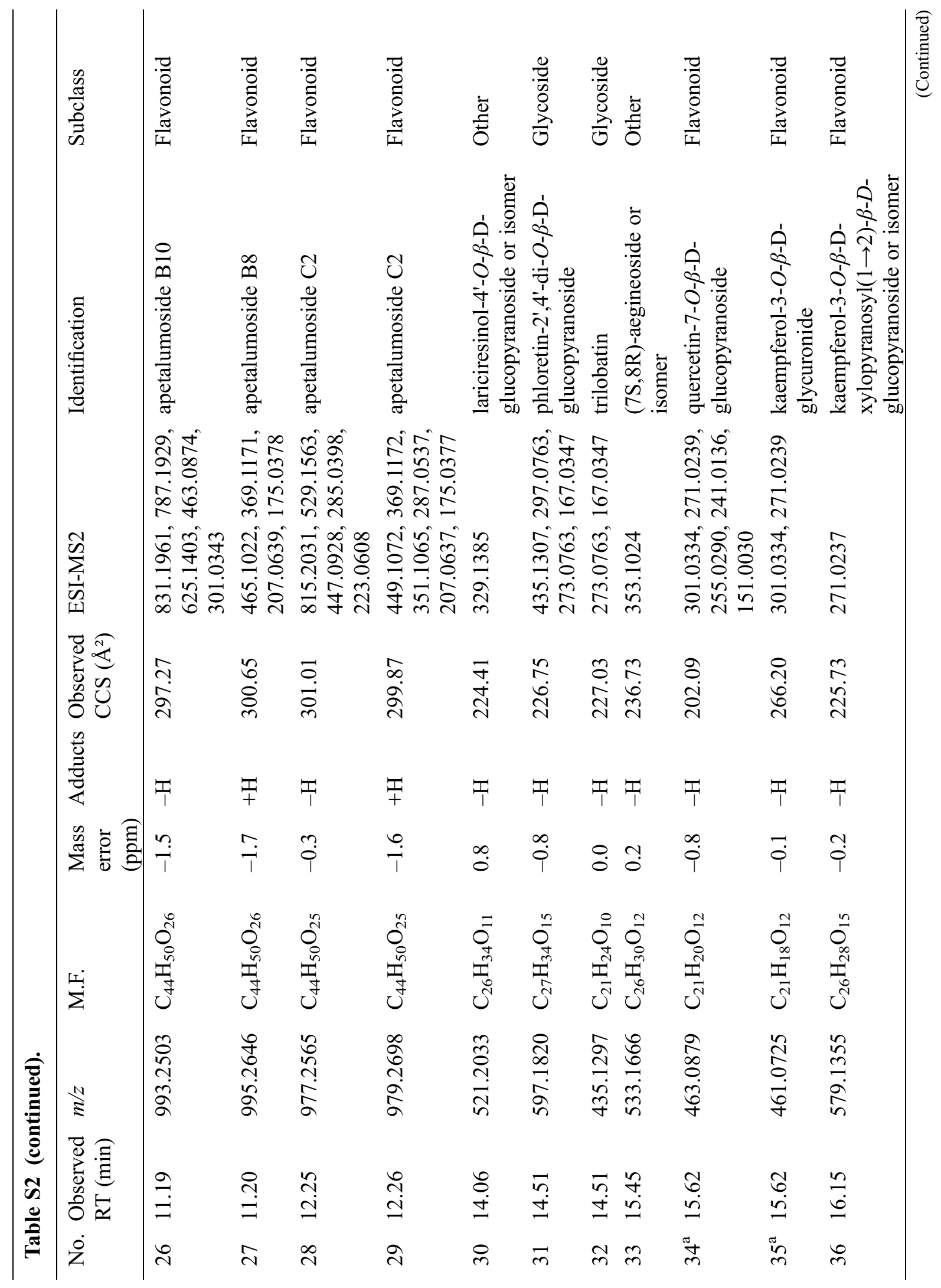




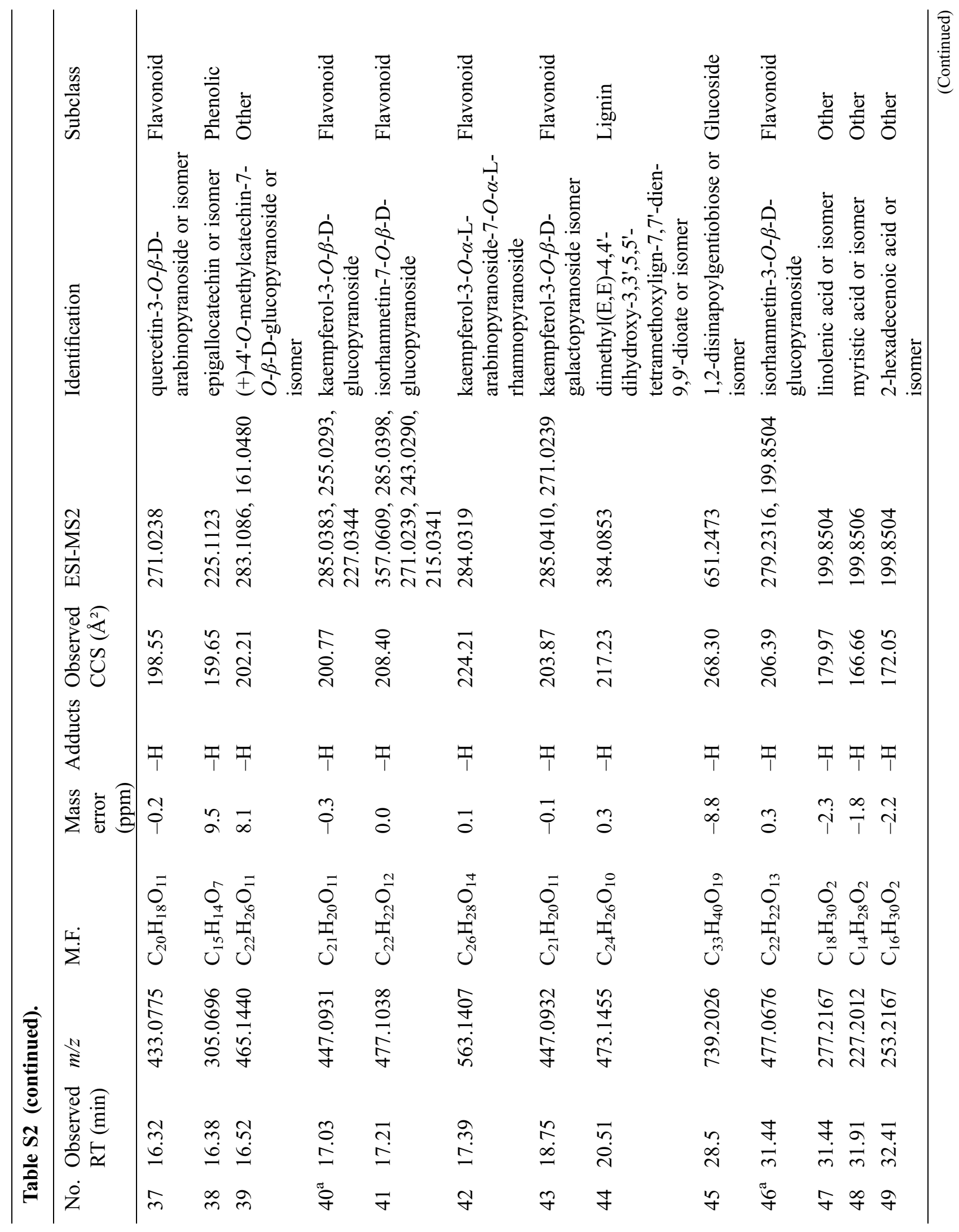


Phyton, 2022, vol.91, no.3

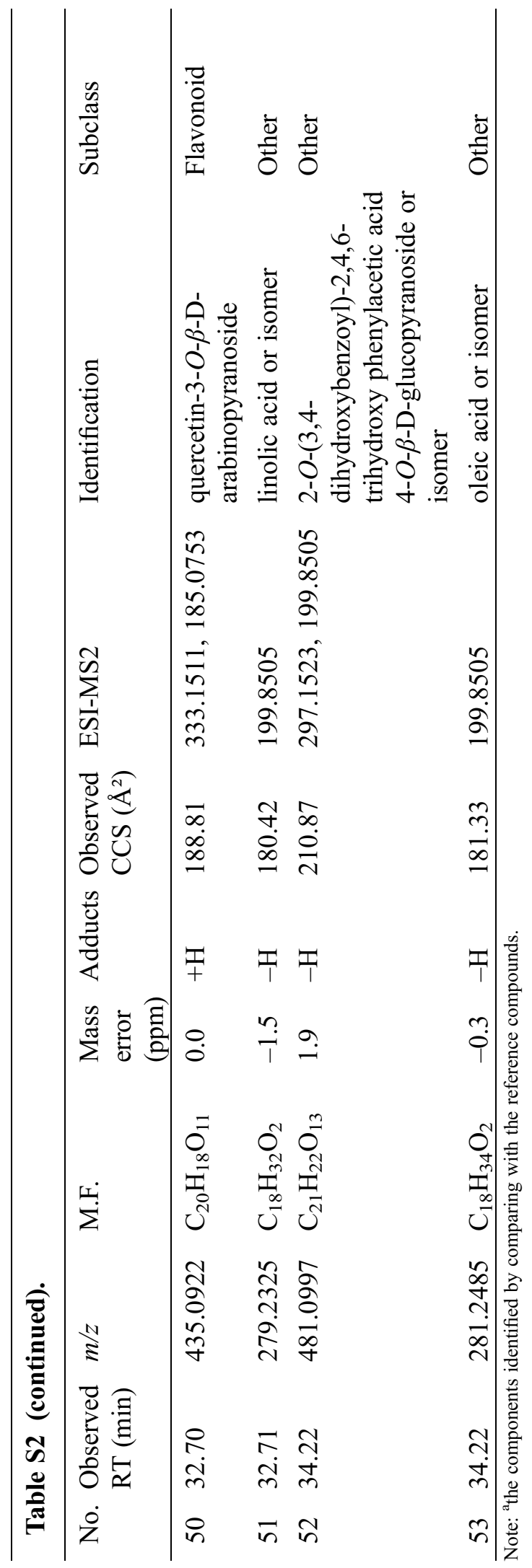

